\title{
28 Research Square \\ The Temporal Pattern of Fibrinogen and Albumin Synthesis Rates Perioperatively in Major Abdominal Surgery
}

Gabriel Dumitrescu ( $\sim$ gabriel.dumitrescu@sll.se)

Karolinska Institutet https://orcid.org/0000-0003-2042-8103

Anna Januszkiewicz

Karolinska Institutet

Anna Ågren

Karolinska Institutet

Maria Magnusson

Karolinska Institutet

Ernesto Sparrelid

Karolinska Institutet

Olav Rooyackers

Karolinska Institutet

Jan Wernerman

Karolinska Institutet

\section{Research}

Keywords: hepatectomy, pancreatectomy, fibrinogen synthesis, albumin synthesis

Posted Date: December 11th, 2020

DOl: https://doi.org/10.21203/rs.3.rs-125414/v1

License: (c) (1) This work is licensed under a Creative Commons Attribution 4.0 International License.

Read Full License 


\section{Abstract}

Background: Plasma fibrinogen and albumin concentrations decrease initially after abdominal surgery. On postoperative days 3-5 fibrinogen concentration returns to preoperative level or even higher, while albumin stays low. Fibrinogen and albumin synthesis may be affected differently following major abdominal surgery related to injury and/or loss of liver tissue.

The objective of the study was to determine fibrinogen and albumin quantitative synthesis rates in patients undergoing hepatectomies or pancreatectomies with intact liver size.

Methods: Patients undergoing liver or pancreatic resection $(n=9+6)$ were studied preoperatively, on postoperative days 1 and 3-5. De novo syntheses of fibrinogen and albumin were determined using the flooding dose technique with ${ }^{2} \mathrm{H}_{5}$-phenylalanine as a tracer. In addition, several biomarkers indicative of fibrinogen utilization were monitored.

Results: After hemi-hepatectomy, fibrinogen synthesis was 2-3-fold higher on postoperative day 1 than preoperatively. On postoperative days 3-5 the synthesis level was still higher than preoperatively. Following major liver resections albumin synthesis was not altered postoperatively compared to preoperative values. After pancreatic resection, on postoperative day 1 fibrinogen synthesis was 5-6-fold higher than preoperatively and albumin synthesis 1.5 -fold higher. On postoperative days $3-5$ the synthesis levels decreased towards the preoperative levels.

Conclusions: De novo synthesis of fibrinogen was markedly stimulated on postoperative day 1 after both hepatectomies and pancreatectomies, while albumin synthesis remained grossly unchanged. The less pronounced changes seen following hepatectomies were possibly related to the loss of liver tissue.

\section{Background}

Major liver resections have become increasingly safer due to the improvement of patient selection and surgical techniques. Still, liver surgery is associated with a risk for postoperative liver insufficiency, which is proportional to the resection size and quality of the remnant liver $(1,2)$. The degree of postoperative liver failure is associated with mortality and is the main cause of fatalities after liver surgery (2-4).

Computer tomography volumetric analysis or magnetic resonance imaging alone or combined with hepatobiliary scintigraphy are used to estimate the functional reserve of the liver and indirectly to assess the risk for postoperative liver failure (5-9). However, the post-resection functional status of the liver, in particular the synthetic function for export proteins of the remnant liver has not been explored.

Fibrinogen is a positive acute-phase reactant which is synthesized mainly in the liver, and after trauma and surgery increases in plasma concentration can be noticed $(10,11)$.

In a previous exploratory study of patients undergoing hepatic surgery, focusing on coagulation, we found that restitution of the reduction of plasma fibrinogen concentration seen on the first postoperative 
day, was related to the size of resection (12). Patients undergoing hemihepatectomy exhibited an overshoot in plasma concentration on the 4th postoperative day, while patients undergoing extended hemihepatectomy did not. This postoperative pattern is also in agreement with other reports (13).

Plasma concertation of albumin on the other hand falls rapidly, within hours after the start of major abdominal surgery (14), and remains low in the early postoperative days although the absolute synthesis rate is not altered perioperatively $(15,16)$.

In principle changes in plasma protein concentration are attributable to changes in synthesis, degradation, and redistribution $(17,18)$. A possible explanation of our findings could be that the smaller liver remnant after an extended resection was not capable to reproduce plasma fibrinogen levels typical of major abdominal surgery because of a compromised synthesis capacity of export proteins.

To explore the mechanism behind the difference in postoperative plasma concentration of fibrinogen related to hepatic resection, we designed a study to assess the de novo synthesis rates of two liver export proteins fibrinogen and albumin in patients undergoing liver resections of variable sizes. Patients undergoing pancreatic resections with intact liver size served as controls. We took in parallel biochemical tests to explore the fibrinogen catabolic pathways and coagulation tests. Thromboelastometry was used to explore coagulability which is affected by fibrinogen $(12,19,20)$ and, possibly, by albumin plasma concentrations $(21,22)$.

\section{Methods}

\section{Subjects}

Patients with an indication for hepatectomy or pancreatic resection at Karolinska Huddinge University Hospital, Stockholm, Sweden, were recruited between September 2017 and May 2019. Smokers and patients with coagulopathies' or under treatment with anticoagulants or platelets aggregation inhibitors were excluded. The study was registered at ANZCTR, ID ACTRN12617000749303.

\section{Protocol}

De novo synthesis rates of fibrinogen and albumin were studied in a longitudinal protocol at three times: preoperatively and on postoperative day 1 and postoperative day $3-5$. The patients who underwent portal vein embolization with two-stage hemi-hepatectomy were studied preoperatively and after the second stage of the operation (postoperative day 1 and 3-5). At the same time, blood samples for coagulation and biochemical tests were collected.

All procedures in conjunction with anesthesia, surgery, and postoperative care were in accord with the local routines at Karolinska University Hospital. The general anesthesia was performed with propofolfentanyl induction and maintenance with sevoflurane-fentanyl. Epidural analgesia was administrated intra- and postoperatively for 5-7 days. Intraoperatively fluids were administrated intravenously in the form of glucose $2.5 \% 1 \mathrm{ml} / \mathrm{kg} /$ hour and Ringer acetate $4 \mathrm{ml} / \mathrm{kg} /$ hour. 
All patients received daily thrombosis prophylaxis with $5000 \mathrm{IU}$ dalteparin (Fragmin $\circledast$ ) at 8:00 p.m. under the entire hospitalization starting the day before the operation.

Preoperatively the patients were investigated in a post-absorptive state (more than 6 hours after a warm meal, and more than 4 hours after coffee or tea. Tap water was allowed without restriction).

Postoperatively enteral nutrition was initiated as soon as possible and was stopped 6 hours before measurement. Intravenous glucose solution, if given, was paused not less than 2 hours before measurement. The intravenous crystalloid solution Ringer acetate 1-2 ml/kg/hour was administrated postoperatively.

\section{Analytic methods for de novo protein synthesis}

We used the flooding dose technique with ${ }^{2} \mathrm{H}_{5}$-phenylalanine for the determination of synthesis rates of fibrinogen and albumin which was described previously $(17,23)$.

Gas chromatography-mass- spectrometry (Agilent 5975C, Agilent, Kista, Sweden) was used to assess i) the enrichment of ${ }^{2} \mathrm{H}_{5}$-phenylalanine in the free phenylalanine pool and ii) the enrichment of ${ }^{2} \mathrm{H}_{5}$ phenylalanine in fibrinogen and albumin.

\section{Calculation of fractional and absolute synthesis rates}

Fractional synthesis rates (FSR), representing the ratio (in percentage) of the intravascular protein mass synthesized per 24 hours, were calculated by dividing the increase of enrichment of the ${ }^{2} \mathrm{H}_{5}$-phenylalanine incorporated in the protein (fibrinogen or albumin) to the area under the curve for ${ }^{2} \mathrm{H}_{5}$-phenylalanine in its free pool (adjusted for the secretion time of the protein) and multiplied by $100(17,23)$.

The absolute synthesis rates (ASR), representing the total amount of protein synthesized per day ( $\mathrm{mg} / \mathrm{kg} /$ day), were calculated by multiplying corresponding FSR with the total plasma protein (fibrinogen or albumin) mass, divided by the bodyweight (23). Plasma volume was estimated using a dedicated formula based on anthropometric data (24).

\section{Laboratory analysis}

On Sysmex Sysmex CS-5100 (Sysmex Corporation, Kobe, Japan): prothrombin time-international normalized ratio (Medirox Owren's PT reagent), activated partial thromboplastin time (aPTT) (Dade Actin FS activated PTT reagent, Siemens), fibrinogen (Clauss method, Dade Thrombin Reagent, Siemens), Ddimer ( Innovance D-Dimer, Siemens), soluble fibrin monomers (Sta-Liatest FM, Stago). Platelet count was performed on Sysmex XN (Sysmex Corporation, Kobe, Japan). Plasma albumin was performed on Cobas 8000 c701 (Roche Diagnostics) with BCP (Bromocresol Purple) reagent (Roche Diagnostics).

On a SpectraMax ${ }^{\circledR}$ i3x Multi-Mode microplate reader: thrombin-antithrombin complexes (Enzygnost TAT micro Kit, Siemens) and fibrinopeptide B (Human Fibrinopeptide B Elisa Kit, Novus Biologicals) 
Thromboelastometry was performed using a ROTEM® delta device (Pentapharm GmbH, Munich, Germany).

\section{Statistics}

Normality was tested with Shapiro-Wilk test. The repeated measures analysis of variances within groups was made by one-way ANOVA, or mixed-effects model-analysis (in case of missing values), and between groups with mixed-effects model analysis. Tukey's method was used for multiple comparisons. Pearsons's correlation test was used for normally distributed variables and Spearman's correlation test for non-normally distributed variables. The level for acceptable statistical significance $(p)$ was $<0.05$.

For the statistical analysis was used GraphPad Prism 8 (GraphPad Software Inc, La Jolla, CA).

\section{Results}

In total 15 patients were enrolled in two groups: 1$)$ large liver resections $(\mathrm{n}=9)$ and 2$)$ pancreas resections $(n=6)$. Patients' characteristics, diagnosis, and surgical interventions are given in Table 1 . 
Table 1

Patients' characteristics, diagnosis and surgical interventions

\begin{tabular}{|c|c|c|}
\hline Patients & Liver surgery & Pancreas surgery \\
\hline No. & 9 & 6 \\
\hline Sex & 5 & 1 \\
\hline Male & 4 & 5 \\
\hline \multicolumn{3}{|l|}{ Female } \\
\hline Age (years)* & $59(43-77)$ & $70(60-78)$ \\
\hline Height $(\mathrm{cm})^{\star}$ & $1.73(1.59-1.85)$ & $1.67(1.61-1.71)$ \\
\hline Weight $(\mathrm{kg})^{*}$ & $69(43-85)$ & $77(61-95)$ \\
\hline Diagnosis & 9 & - \\
\hline Colorectal metastasis & - & 5 \\
\hline IPMN** & - & 1 \\
\hline \multicolumn{3}{|l|}{ Pancreas cystic tumor } \\
\hline Performed surgery & 1 & - \\
\hline Resection of two liver segments and & 5 & - \\
\hline right colectomy & 1 & - \\
\hline Right hemihepatectomy & 2 & - \\
\hline Extended right hemihepatectomy & - & 4 \\
\hline 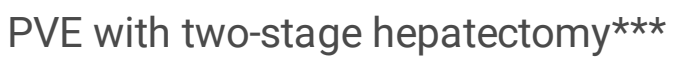 & - & 2 \\
\hline \multicolumn{3}{|l|}{ Distal pancreatectomy } \\
\hline \multicolumn{3}{|l|}{ Total pancreatectomy } \\
\hline Postoperative thrombosis ${ }^{\star \star \star \star}$ & 0 & 1 \\
\hline \multicolumn{3}{|l|}{ *Median (range) } \\
\hline \multicolumn{3}{|c|}{$\star \star \mid P M N=$ Intraductal papillary mucinous neoplasm } \\
\hline \multicolumn{3}{|c|}{$\star \star \star$ Portal vein embolization/ligation (PVE) with two-stage right hemihepatectomy } \\
\hline$\star \star \star \star$ Portal vein thrombosis & & \\
\hline
\end{tabular}

\section{Plasma concentrations of fibrinogen and albumin}


In Figs. 1A and 2A plasma concentrations of fibrinogen and albumin are given. The two groups exhibited different patterns. For fibrinogen, following hepatectomy, a decrease on postoperative day 1 was followed by restitution to preoperative values on days $3-5$. In contrast, the patients who underwent pancreatectomy had unaltered concentrations of fibrinogen on postoperative day 1 followed by an overshoot on postoperative days $3-5$. For albumin, there was a decrease in plasma concentration for both groups on postoperative day 1 , larger for the pancreatectomy group, which remained low compared to preoperative values on postoperative days $3-5$.

Mixed-effects model analyses between the two groups are given in Fig. 3 (panel A). The differences were not statistically significant for trends of fibrinogen plasma concentrations. Differences in albumin plasma concentration trends between the two groups were attributed to the lower preoperative values in patients undergoing liver surgery.

\section{De novo synthesis of fibrinogen and albumin}

Results for fibrinogen synthesis are given in Fig. 1B. The fractional synthesis rates were markedly increased on postoperative day 1 for both groups of patients, followed by a relative lowering of values on postoperative days $3-5$. The interindividual scatter was larger, so the values on postoperative days $3-5$ remained more marginally elevated for hepatectomies but were not different from preoperative ones for pancreatectomy. When values for absolute synthesis rate were calculated, they followed the same pattern.

Albumin synthesis rates are given in Fig. 2B. For the hepatectomy group the synthesis rates were unaltered on postoperative day 1 , but the fractional synthesis rate increased on postoperative days $3-5$. The pancreatectomy group showed an increase in both fractional and absolute synthesis rate of albumin on postoperative day 1 , which remained higher for the fractional synthesis rate, but not for the absolute synthesis rate on postoperative days 3-5.

Figure 1. The fibrinogen plasma concentrations (panel A) and synthesis rates (panel B) in all patients undergoing liver surgery $(n=9)$ and pancreas surgery $(n=6)$. The individual values are depicted as black bold points. Levels of statistical significance for the ANOVA (or mixed-effects model analysis within groups) are given in the right upper corner. For multiple comparisons $*, * \star, \star \star \star, * \star \star \star$ denotes the statistical significance $p<0.05, p<0.01, p<0.001$ and $<0.0001$ respectively of the difference from preoperative values, while \# have the same significance from postoperative day 1 .

Figure 2. The albumin plasma concentrations (panel A) and synthesis rates (panel B) in all patients undergoing liver surgery $(n=9)$ and pancreas surgery $(n=6)$. The individual values are depicted as black bold points. Levels of statistical significance for the ANOVA (or mixed-effects model analysis within

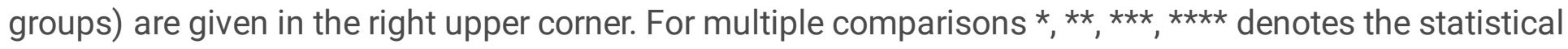
significance $p<0.05, p<0.01, p<0.001$ and $<0.0001$ respectively of the difference from preoperative values, while \# have the same significance from postoperative day 1 . 
Figure 3. The temporal pattern of fibrinogen and albumin plasma concentrations (panel A) and synthesis rates (panel $B$ ) in patients undergoing major liver surgery $(n=9)$ (depicted in red) and pancreas resection $(n=6)$ (depicted in blue). Values are provided as the mean +0.95 confidence intervals and the level of statistical significance for mixed-effects model analysis between groups are given in the upper right corner.

Mixed-effects model analyses between the two groups are given in Fig. $\mathbf{3}$ (panel B). There were no significant differences between pancreas and liver surgery regarding the synthesis of fibrinogen, but for albumin the synthesis rate trends were different.

\section{Biochemical and coagulation analyses}

Laboratory analyses are given in Table 2. The bilirubin plasma concentrations were increased following liver surgery during the entire observed postoperative period, while in pancreas surgery they were unchanged. For PT-INR there were increased values both for hepatectomy and pancreatectomy patients especially on postoperative day 1. APTT and platelet count were not altered postoperatively regardless of the type of operation. 
Table 2

Laboratory tests in patients undergoing liver surgery $(n=9)$ and pancreas surgery $(n=6)$ given as median (range).

\begin{tabular}{|c|c|c|c|c|c|c|c|}
\hline & Ref. range & & Day 0 & Day 1 & Day 3-5 & $p_{0}$ & p \\
\hline \multirow[t]{2}{*}{ Bilirubin } & $<26 \mu \mathrm{mol} / \mathrm{ml}$ & L & $\begin{array}{l}10(5- \\
17)\end{array}$ & $\begin{array}{l}21(9- \\
52) *\end{array}$ & $\begin{array}{l}20(5- \\
44) *\end{array}$ & 0.02 & 0.10 \\
\hline & & $P$ & $6(4-9)$ & $9(4-15)$ & $6(4-15)$ & 0.3 & \\
\hline \multirow[t]{2}{*}{ Albumin } & $34-45 \mathrm{~g} / \mathrm{L}$ & L & $\begin{array}{l}33(29- \\
43)\end{array}$ & $\begin{array}{l}25(20- \\
35) * *\end{array}$ & $\begin{array}{l}25(20- \\
32) * *\end{array}$ & $\begin{array}{l}< \\
0.01\end{array}$ & $<.01$ \\
\hline & & $P$ & $\begin{array}{l}38(35- \\
42)\end{array}$ & $\begin{array}{l}26(25- \\
30) * \star *\end{array}$ & $\begin{array}{l}26(23- \\
28) * \star \star\end{array}$ & $\begin{array}{l}< \\
0.01\end{array}$ & \\
\hline \multirow[t]{2}{*}{ Fibrinogen } & $2-4.2 \mathrm{~g} / \mathrm{L}$ & L & $\begin{array}{l}3.7(3- \\
5.3)\end{array}$ & $\begin{array}{l}2.4(1.8- \\
3.7) * \star\end{array}$ & $\begin{array}{l}\text { 4(2.8- } \\
4.6) \# \#\end{array}$ & $\begin{array}{l}< \\
0.01\end{array}$ & 0.06 \\
\hline & & $P$ & $\begin{array}{l}3.9(3.1- \\
5.3)\end{array}$ & $\begin{array}{l}3.5(2.8- \\
4.4)\end{array}$ & $\begin{array}{l}\text { 5.9(3.2- } \\
7.5) * \#\end{array}$ & $\begin{array}{l}<.01 \\
0.01\end{array}$ & \\
\hline \multirow[t]{2}{*}{ PT-INR } & $<1,2$ & L & $\begin{array}{l}1.0 \\
(0.9- \\
1.1)\end{array}$ & $\begin{array}{l}1.5(1.4- \\
1.9)^{\star \star \star}\end{array}$ & $\begin{array}{l}1.3(1.1- \\
1.5) \star \#\end{array}$ & $\begin{array}{l}<.01 \\
0.01\end{array}$ & 0.04 \\
\hline & & $P$ & $\begin{array}{l}0.9 \\
(0.9- \\
1.2)\end{array}$ & $\begin{array}{l}1.2(1.1- \\
1.6) \star \star\end{array}$ & $\begin{array}{l}1.2(1- \\
1.4) * \star\end{array}$ & $\begin{array}{l}< \\
0.01\end{array}$ & \\
\hline \multirow[t]{2}{*}{ APT } & $28-40 \mathrm{~s}$ & L & $\begin{array}{l}23(22- \\
29)\end{array}$ & $\begin{array}{l}25(24- \\
32)\end{array}$ & $\begin{array}{l}25(22- \\
32)\end{array}$ & 0.1 & 0.7 \\
\hline & & $P$ & $\begin{array}{l}23(22- \\
26)\end{array}$ & $\begin{array}{l}25(22- \\
28)\end{array}$ & $\begin{array}{l}25(21- \\
34)\end{array}$ & 0.5 & \\
\hline \multirow[t]{2}{*}{ Platelets count } & $\begin{array}{l}165-387 \times \\
10(9) / L\end{array}$ & L & $\begin{array}{l}180 \\
(149- \\
358)\end{array}$ & $\begin{array}{l}177 \\
(112- \\
214)\end{array}$ & $\begin{array}{l}167 \\
(138- \\
250)\end{array}$ & 0.25 & 0.7 \\
\hline & & $P$ & $\begin{array}{l}233 \\
(188- \\
322)\end{array}$ & $\begin{array}{l}168 \\
(154- \\
305) \text { * }\end{array}$ & $\begin{array}{l}202 \\
(111- \\
441)\end{array}$ & 0.29 & \\
\hline \multirow[t]{2}{*}{$\begin{array}{l}\text { Thrombin- } \\
\text { antithrombin } \\
\text { complexes(TAT) }\end{array}$} & $8.8 \pm 1.8 \mathrm{pg} / \mathrm{ml}$ & $P$ & $\begin{array}{l}5.8(3- \\
11.3)\end{array}$ & $\begin{array}{l}27.7 \\
(11.9- \\
77.3) \text { * }\end{array}$ & $\begin{array}{l}6.9(6.4- \\
27) \#\end{array}$ & 0.01 & 0.95 \\
\hline & & L & $\begin{array}{l}9.7 \\
(2.4- \\
57)\end{array}$ & $\begin{array}{l}36(11- \\
76) *\end{array}$ & $\begin{array}{l}15.4 \\
(5.2- \\
32.4)\end{array}$ & 0.03 & \\
\hline \multicolumn{8}{|c|}{$\begin{array}{l}\text { Levels of statistical significance }\left(p_{0}\right) \text { for the ANOVA (or mixed-effects analysis within groups) and }(p) \\
\text { for mixed-effects model analysis between groups are given. ( } L=\text { liver surgery, } P=\text { pancreas surgery). } \\
\text { For multiple comparisons } \star, \star \star, * \star \star \\
\text { and }<0.0001 \text { respectively of the difference from preoperative values, while } \# \text { have the same } \\
\text { significance from postoperative day } 1 \text {. }\end{array}$} \\
\hline
\end{tabular}




\begin{tabular}{|c|c|c|c|c|c|c|c|}
\hline & Ref. range & & Day 0 & Day 1 & Day 3-5 & $\mathrm{P}_{0}$ & p \\
\hline \multirow[t]{2}{*}{ Soluble fibrin } & $<9 \mathrm{mg} / \mathrm{L}$ & L & $\begin{array}{l}5.0(1- \\
7)\end{array}$ & $\begin{array}{l}51(5- \\
150) \text { ** }\end{array}$ & $\begin{array}{l}8(2- \\
150)\end{array}$ & 0.01 & \multirow[t]{2}{*}{0.03} \\
\hline & & $P$ & $\begin{array}{l}3.5(1- \\
5)\end{array}$ & $6(5-17)$ & $\begin{array}{l}5.5(2- \\
12)\end{array}$ & 0.07 & \\
\hline \multirow[t]{2}{*}{ Fibrinopeptide $B(f p B)$} & $\begin{array}{l}\mu \mathrm{g} / \mathrm{ml} \text { (no ref. } \\
\text { range available) }\end{array}$ & L & $\begin{array}{l}44(31- \\
64)\end{array}$ & $\begin{array}{l}50(50- \\
78)\end{array}$ & $\begin{array}{l}45(32- \\
64)\end{array}$ & 0.57 & \multirow[t]{2}{*}{0.44} \\
\hline & & $P$ & $\begin{array}{l}44(30- \\
60)\end{array}$ & $\begin{array}{l}42(39- \\
53)\end{array}$ & $\begin{array}{l}38(28- \\
41)\end{array}$ & 0.29 & \\
\hline \multirow[t]{2}{*}{ D-dimer } & $<0.7 \mathrm{mg} / \mathrm{L}$ & L & $\begin{array}{l}0.8 \\
(0.4- \\
1.7)\end{array}$ & $\begin{array}{l}6.1(0.9- \\
19.2) \star \star\end{array}$ & $\begin{array}{l}8.2(4.7- \\
14.8) \star \star\end{array}$ & $\begin{array}{l}<.01 \\
0.01\end{array}$ & \multirow[t]{2}{*}{0.07} \\
\hline & & $P$ & $\begin{array}{l}0.6 \\
(0.2- \\
1.7)\end{array}$ & $\begin{array}{l}3.3(1.9- \\
6.4) *\end{array}$ & $\begin{array}{l}4.0(1.5- \\
6.7) *\end{array}$ & 0.02 & \\
\hline \multicolumn{8}{|c|}{ 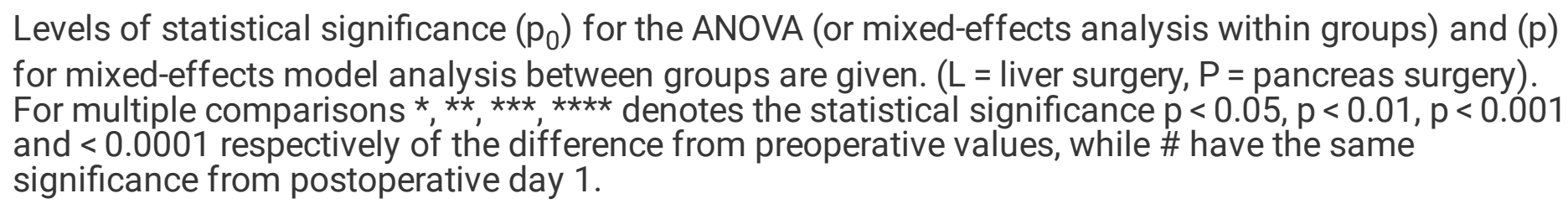 } \\
\hline
\end{tabular}

Following both liver and pancreas surgery thrombin-antithrombin complexes (TAT) levels were higher on postoperative day 1 than preoperatively, decreasing towards normalization on postoperative days 3-5. Soluble fibrin concentrations were increased on postoperative day 1 only in liver surgery, while the fibrinopeptide B ( $f p B)$ levels were unaltered in both groups regardless of the postoperative day. D-dimer concentrations increased postoperatively, more accentuated following liver surgery. There were no significant differences between liver and pancreas surgery regarding the coagulation markers except for soluble fibrin. A graphical representation of data for TAT, soluble fibrin, $\mathrm{fpB}$ and D-dimer is given is given in an additional file (see Additional file 1).

\section{The results from the ROTEM $\AA^{\text {analyses }}$}

The thromboelastometric results are given in an additional file (see Additional file 2). For both groups, the mean values of most ROTEM® parameters remained within the normal range during the entire study period. The exception was MCF-FIBTEM values which tended to exceed the hypercoagulability on POD 35. There were no significant differences between the two groups regarding the temporal pattern.

The small temporal changes regarding CFT and MCF were parallel with the fibrinogen plasma concentrations and not with fibrinogen synthesis rates which were moving in opposite directions (see Additional file 2).

\section{Correlations}


At any of the three determinations in liver or pancreas surgery, there were no correlations between fibrinogen plasma concentrations (or changes in plasma concentrations) and FSR or ASR of fibrinogen, or between plasma albumin concentrations and FSR or ASR of albumin.

No correlations were found between the ROTEM parameters and fibrinogen or albumin synthesis rates in any group at any time.

There were no correlations between bilirubin plasma concentrations or PT-INR and fibrinogen or albumin synthesis rates regardless of the type of operation.

\section{Hypercoagulability signs}

On POD 3-5 most patients who underwent pancreatectomy had plasma fibrinogen concentrations, as well MCF FIBTEM, over the normal range (see Additional file 2).

Two patients operated with distal pancreatectomy had on POD 4 and 5 respectively the ROTEM parameter MCF increased over the normal in all three curves INTEM, EXTEM and FIBTEM, and fibrinogen plasma level was over $6 \mathrm{~g} / \mathrm{L}$. In one of these patients, a routine CT scan on postoperative day 8 disclosed a fresh portal vein thrombosis.

\section{Discussions}

The focus of our present study was to explore how plasma concentrations and de novo synthesis of two major hepatic export proteins were affected perioperatively by major abdominal surgery with and without a reduction in liver mass.

Following both major liver resections and pancreatic resections there was a dramatic increase in the de novo synthesis rate of fibrinogen on postoperative day 1 , most pronounced in the pancreatectomy group with an intact liver mass. As far as we are aware, this is the first time this physiological response has been described. Postoperative levels (or change in levels) of plasma fibrinogen concentrations were not indicators for levels (or change in levels) of synthesis. On the contrary, plasma concentrations were marginally decreased (in all subjects undergoing hepatectomy) or unaltered (pancreatectomy) on postoperative day 1 , which was in agreement with previous studies $(12,13,25)$. At this time-point the plasma fibrinogen concentrations likely were on an upward trend, as their nadir, according to previous studies, is at the end of the operation $(13,26)$. On postoperative days $3-5$ this increase in de novo synthesis was levelled off, but plasma concentration showed an overshoot compared to preoperative values in the pancreatectomy patients with the intact liver mass. The indirect biomarkers of fibrinogen utilization showed an activation on postoperative day 1 (TAT and soluble fibrin), and a more prolonged activation (D-dimer), where the difference between hepatectomy and pancreatectomy groups was equivocal. For coagulation competence, the global measures via tromboelastometry showed balanced coagulation for both groups of patients. 
The concentrations of plasma fibrinogen on postoperative day 1 can only be explained through the enhanced use of important amounts of de novo synthesized fibrinogen, which was on average $2 \mathrm{~g} /$ day for hepatectomies, and $6 \mathrm{~g} /$ day for pancreatectomies. Taking into consideration the fibrinogen half-time, which in normal conditions is around 4 days (27), this additional output of fibrinogen should have been noticed on plasma concentrations unless a fast utilization occurred. The fibrinogen exit from the plasma pool is commonly associated with fibrin formation. The utilization of fibrinogen in the coagulation process is increased intraoperatively compared to normal conditions (28). In our study TAT levels on postoperative day 1 indicated a certain coagulation activation and implicitly an increased fibrinogen utilization, to the same extent in liver and pancreas surgery. However, the levels of soluble fibrin monomers showed that the ongoing cleavage of fibrinogen by thrombin, which is exacerbated intraoperatively $(29,30)$, decreased hastily after pancreatectomies, while following major liver surgery the process was slower. Although the magnitude of the active fibrin formation is hard to be estimated, as indicated by $\mathrm{fpB}$ levels, this seems not to be high on postoperative day 1 and onwards. There is evidence that even under trauma or surgical operations fibrin formation might not be the main utilization pathway for fibrinogen (28). Hence, alternative utilization may contribute to the plasma fibrinogen levels. Unfortunately, although intuited, these pathways are not described until now $(31,32)$. An increased transcapillary escape might also be involved.

Plasma fibrinogen is essential for balanced coagulation. ROTEM mostly showed balanced coagulation following both types of surgery, which for liver surgery is in agreement with previous studies $(12,26)$. However, following pancreatectomies, increased plasma fibrinogen concentrations on postoperative days 3-5 affected the ROTEM firmness parameter MCF towards the hypercoagulability area. The portal vein thrombosis observed in one of the patients with signs of hypercoagulability in three ROTEM parameters might be a consequence of a pro-thrombotic state generated by high plasma fibrinogen concentration.

For albumin there is a well-characterized redistribution starting already during the surgical procedure, resulting in a sharp decrease in plasma concentrations $(14,15)$. There are no major losses of albumin by degradation or loss out of the body to explain the decrease in concentration, so the initial step is redistribution to the extravascular space. De novo synthesis rates are unaffected or increased. In the hepatectomy group, the synthesis rate for albumin was unchanged under the entire explored period. By all means, taking into consideration the massive loss of liver tissue following hemihepatectomies, there was indeed an increase in albumin synthesis per tissue unit in the remnant liver. In this study on postoperative day 1 there was an increase of albumin synthesis rates in the pancreatectomy group, compared to earlier studies when they are found unaltered on postoperative day 2 (15). The increase of the novo synthesis of albumin, following pancreatectomies on postoperative day 1 over the preoperative baseline, was in absolute value around $4 \mathrm{~g} /$ day; this was insufficient to influence plasma albumin concentrations.

The albumin synthesis is suggested to be regulated primarily by the colloid osmotic pressure (18). Inflammation in general has a stimulatory effect on albumin synthesis as well (33). In our study albumin synthesis was stimulated on postoperative day 1 but not on postoperative days $3-5$, which, under the 
condition of constant low albumin plasma concentrations, favors the inflammation as a stimulatory factor.

It was within our hypothesis that any differences in plasma concentrations of fibrinogen between the two groups of surgical patients studied may be attributable to a difference in liver mass resulting from the surgical procedure. However, there were also some other differences between the two groups regarding fibrinogen utilization, so it is not possible to conclude anything to be attributable to the difference in liver mass. Still, we intended to have a comparable surgical trauma in the upper abdomen to see what was related to the surgical procedure per se and the reduction in liver mass.

Our findings in this descriptive observational study gain their full meaning when related to their clinical contexts. A predictable postoperative rate of increase in plasma fibrinogen may affect the decision on fibrinogen supplementation. Studies performed in cardiac surgery or cystectomy with massive bleeding show that during the first 24 postoperative hours the plasma fibrinogen concentrations increase at a predictable rate if fibrinogen is not supplemented $(34,35)$. On postoperative day 1 , they reach the same values as preoperative, regardless of the administration or not of fibrinogen concentrate (34-36), suggesting that the administration of fibrinogen in excess is disposed by the organism, or slows the synthesis. We showed that the liver synthesis of fibrinogen following major abdominal surgery is modulated postoperatively to eventually reach the levels of plasma fibrinogen to which the organism is accustomed, which are the preoperative ones. This makes the postoperative plasma fibrinogen concentrations predictable even following hemihepatectomies with no risk for post-hepatectomy liver failure related to low fibrinogen availability. Concerning albumin, in our patients following hepatectomies the tendency of albumin synthesis to increase towards postoperative days $3-5$, when inflammation stimuli were, by all means, negligible, suggested a good synthetic function of the regenerating liver. Studies demonstrate that the regeneration of the liver tissue volume is considerable during the first week after liver resections (37), but there were no reports until now regarding the in-vivo synthetic functionality of the new liver tissue in humans. The role of fibrinogen in liver regeneration following hepatectomies is discussed increasingly (38) and our study of fibrinogen synthesis in the remnant liver holds significance even in this area of research.

The strengths of our study are the techniques to assess the synthesis rate of liver export proteins quantitatively and to put these in relation to functional parameters related to plasma concentrations and to liver function in connection with surgical trauma. There are also some limitations to our study, including the relatively small number of subjects available, which meant that describing the synthesis trends for patients following extended hemihepatectomies was unattainable. Another notable limitation was the lack of techniques to quantitatively assess the disappearance rates for fibrinogen and albumin in vivo.

In this study we were able to report patterns for fibrinogen and albumin in terms of plasma concentrations and de novo synthesis perioperatively in conjunction with larger upper abdominal surgery with and without reduction of liver mass. For fibrinogen, there was a dramatic increase in de novo 
synthesis rate on postoperative day 1 , although plasma concentrations were decreased following liver resections or unaltered following pancreatic resections. Also, on postoperative days $3-5$ the hepatectomy group had a higher de novo synthesis rate of fibrinogen compared to the preoperatively values. By the end, the results of these synthesis modifications were a return to the preoperative plasma fibrinogen concentrations in the hepatectomy group, and an overshoot in plasma concentrations of fibrinogen in the pancreatectomy group with an intact liver mass. Albumin de novo synthesis was maintained or marginally increased in contrast to the dramatically decreased concentrations. So, in spite of an over $50 \%$ reduction in liver mass after hemihepatectomy the characteristic response in changes in concentrations and de novo synthesis of fibrinogen and albumin perioperatively remained grossly similar after a major reduction in liver mass as compared to surgery of comparative size. However, the alterations were less pronounced after hepatectomy compared to pancreatectomy, possibly related to the reduced liver mass.

\section{Conclusion}

The well-known drops in plasma concentrations of fibrinogen and albumin immediately following major abdominal surgery were associated with increases in the de novo synthesis rates of both proteins. For fibrinogen the increase was dramatic resulting in a restitution of fibrinogen plasma concentration within a few days. The relation between the plasma concentration and upregulated synthesis rate suggested that utilization of fibrinogen in the postoperative period also to be increased. For albumin the well-known altered distribution volume, made plasma concentration to stay low despite the maintained or even increased de novo synthesis rate. Despite the loss of a substantial portion of liver tissue in the hepatectomy group, the above described increase in fibrinogen synthesis rate was not different from the pancreatectomy group with intact liver tissue.

\section{Abbreviations}

aPTT = activated partial thromboplastin time; $\mathrm{ASR}=$ absolute synthesis rate; $\mathrm{CT}, \mathrm{CFT}, \mathrm{MCF}=\mathrm{ROTEM}$ parameters; $\mathrm{fpB}=$ fibrinopeptide $\mathrm{B} ; \mathrm{FSR}=$ fractional synthesis rate; $I P M N=$ intraductal papillary mucinous neoplasm; PVE = portal vein embolization/ligation; ROTEM= thromboelastometry; TAT = thrombinantithrombin complexes.

\section{Declarations}

Ethics approval and consent to participate: The patients gave written consent after being informed about the study protocol orally and in writing. The protocol was approved by the Regional Ethics Committee in Stockholm, Sweden, and was in accordance with the Declaration of Helsinki of 2013.

Consent for publication: Not applicable

Availability of data and materials: The datasets used and/or analysed during the current study are available from the corresponding author on reasonable request. 
Funding: The study was supported by grants from the Stockholm County Council and Swedish Research Council. The funders had no role in study design, data collection and analysis, decision to publish, or preparation of the manuscript.

Authors' contributions: GD, AJ, Å, MM, JW design of the study; GD performed data collection; GD, JW performed analysis of data; GD, Å, MM, OR, JW contributed to interpretation of data; GD and JW were major contributors in writing the manuscript, GD, AJ, Å, MM, ES, OR, JW have drafted the manuscript or substantively revised it. All authors read and approved the final manuscript.

Acknowledgements: The authors acknowledge Janelle Cederlund and Kristina Kilsand for the skilled nursing assistance, surgery research nurses Maura Krook and loana Apostolopoulou for the logistic help, Maria Klaude, Christina Hebert, Towe Jacobsson, and Nicolas Tardif for the expertise and laboratory analyses regarding protein synthesis, Dr. Niklas Bark for the advice regarding the coagulation activation markers and Dr. Åke Norberg for the valuable statistically advices given.

\section{References}

1. Balzan S, Belghiti J, Farges O, Ogata S, Sauvanet A, Delefosse D, et al. The "50-50 criteria" on postoperative day 5: an accurate predictor of liver failure and death after hepatectomy. Annals of surgery. 2005;242(6):824-8, discussion 8-9.

2. Paugam-Burtz C, Janny S, Delefosse D, Dahmani S, Dondero F, Mantz J, et al. Prospective validation of the "fifty-fifty" criteria as an early and accurate predictor of death after liver resection in intensive care unit patients. Annals of surgery. 2009;249(1):124-8.

3. Mullen JT, Ribero D, Reddy SK, Donadon M, Zorzi D, Gautam S, et al. Hepatic insufficiency and mortality in 1,059 noncirrhotic patients undergoing major hepatectomy. J Am Coll Surg. 2007;204(5):854-62. discussion 62 - 4.

4. Reddy SK, Barbas AS, Turley RS, Steel JL, Tsung A, Marsh JW, et al. A standard definition of major hepatectomy: resection of four or more liver segments. HPB: the official journal of the International Hepato Pancreato Biliary Association. 2011;13(7):494-502.

5. Suda K, Ohtsuka M, Ambiru S, Kimura F, Shimizu H, Yoshidome H, et al. Risk factors of liver dysfunction after extended hepatic resection in biliary tract malignancies. American journal of surgery. 2009;197(6):752-8.

6. Chapelle T, Op de Beeck B, Roeyen G, Bracke B, Hartman V, De Greef K, et al. Measuring future liver remnant function prior to hepatectomy may guide the indication for portal vein occlusion and avoid posthepatectomy liver failure: a prospective interventional study. HPB: the official journal of the International Hepato Pancreato Biliary Association. 2017;19(2):108-17.

7. Schindl MJ, Redhead DN, Fearon KC, Garden OJ, Wigmore SJ, Edinburgh Liver S, et al. The value of residual liver volume as a predictor of hepatic dysfunction and infection after major liver resection. 
Gut. 2005;54(2):289-96.

8. Wibmer A, Prusa AM, Nolz R, Gruenberger T, Schindl M, Ba-Ssalamah A. Liver failure after major liver resection: risk assessment by using preoperative Gadoxetic acid-enhanced 3-T MR imaging. Radiology. 2013;269(3):777-86.

9. Ribero D, Chun YS, Vauthey JN. Standardized liver volumetry for portal vein embolization. Semin Intervent Radiol. 2008;25(2):104-9.

10. Colley CM, Fleck A, Goode AW, Muller BR, Myers MA. Early time course of the acute phase protein response in man. J Clin Pathol. 1983;36(2):203-7.

11. Brochner AC, Toft P. Pathophysiology of the systemic inflammatory response after major accidental trauma. Scand J Trauma Resusc Emerg Med. 2009;17:43.

12. Dumitrescu G, Januszkiewicz A, Agren A, Magnusson M, Isaksson B, Wernerman J. The temporal pattern of postoperative coagulation status in patients undergoing major liver surgery. Thromb Res. 2015;136(2):402-7.

13. De Pietri L, Montalti R, Begliomini B, Scaglioni G, Marconi G, Reggiani A, et al. Thromboelastographic changes in liver and pancreatic cancer surgery: hypercoagulability, hypocoagulability or normocoagulability? Eur J Anaesthesiol. 2010;27(7):608-16.

14. Norberg A, Rooyackers O, Segersvard R, Wernerman J. Leakage of albumin in major abdominal surgery. Crit Care. 2016;20(1):113.

15. Norberg A, Rooyackers O, Segersvard R, Wernerman J. Albumin Kinetics in Patients Undergoing Major Abdominal Surgery. PLoS One. 2015;10(8):e0136371.

16. Komaromi A, Estenberg U, Hammarqvist F, Rooyackers O, Wernerman J, Norberg A. Simultaneous assessment of the synthesis rate and transcapillary escape rate of albumin in inflammation and surgery. Crit Care. 2016;20(1):370.

17. Ballmer PE, McNurlan MA, Milne E, Heys SD, Buchan V, Calder AG, et al. Measurement of albumin synthesis in humans: a new approach employing stable isotopes. Am J Physiol. 1990;259(6 Pt 1):E797-803.

18. Levitt DG, Levitt MD. Human serum albumin homeostasis: a new look at the roles of synthesis, catabolism, renal and gastrointestinal excretion, and the clinical value of serum albumin measurements. Int J Gen Med. 2016;9:229-55.

19. Dumitrescu G, Januszkiewicz A, Agren A, Magnusson M, Wahlin S, Wernerman J. Thromboelastometry. Relation to the severity of liver cirrhosis in patients considered for liver transplantation. Medicine. 2017;96(23):e7101.

20. Vucelic D, Jesic R, Jovicic S, Zivotic M, Grubor N, Trajkovic G, et al. Comparison of standard fibrinogen measurement methods with fibrin clot firmness assessed by thromboelastometry in patients with cirrhosis. Thromb Res. 2015;135(6):1124-30.

21. Jorgensen KA, Stoffersen E. On the inhibitory effect of albumin on platelet aggregation. Thromb Res. $1980 ; 17(1-2): 13-8$. 
22. Rasmussen KC, Hojskov M, Johansson PI, Kridina I, Kistorp T, Salling L, et al. Impact of Albumin on Coagulation Competence and Hemorrhage During Major Surgery: A Randomized Controlled Trial. Medicine. 2016;95(9):e2720.

23. Dumitrescu G, Komaromi A, Rooyackers O, Klaude M, Hebert C, Wernerman J, et al. Repeated quantitative measurements of De Novo synthesis of albumin and fibrinogen. PLoS One. 2017;12(3):e0174611.

24. Nadler SB, Hidalgo JH, Bloch T. Prediction of blood volume in normal human adults. Surgery. 1962;51(2):224-32.

25. Louis SG, Barton JS, Riha GM, Orloff SL, Sheppard BC, Pommier RF, et al. The international normalized ratio overestimates coagulopathy in patients after major hepatectomy. American journal of surgery. 2014;207(5):723-7.

26. Mallett SV, Sugavanam A, Krzanicki DA, Patel S, Broomhead RH, Davidson BR, et al. Alterations in coagulation following major liver resection. Anaesthesia. 2016;71(6):657-68.

27. Collen D, Tytgat GN, Claeys H, Piessens R. Metabolism and distribution of fibrinogen. I. Fibrinogen turnover in physiological conditions in humans. Br J Haematol. 1972;22(6):681-700.

28. Nossel HL. Radioimmunoassay of fibrinopeptides in relation to intravascular coagulation and thrombosis. N Engl J Med. 1976;295(8):428-32.

29. Weinberg L, Scurrah N, Parker FC, Dauer R, Marshall J, McCall P, et al. Markers of coagulation activation after hepatic resection for cancer: evidence of sustained upregulation of coagulation. Anaesthesia intensive care. 2011;39(5):847-53.

30. Kambayashi J, Sakon M, Yokota M, Shiba E, Kawasaki T, Mori T. Activation of coagulation and fibrinolysis during surgery, analyzed by molecular markers. Thromb Res. 1990;60(2):157-67.

31. Sherman LA. Catabolism of fibrinogen and its derivatives. Thromb Haemost. 1977;38(4):809-22.

32. Aliberti G, Pulignano I, Schiappoli A, Ceci F, Tritapepe L, Di Giovanni C, et al. Fibrinogen metabolism in the lungs. Metabolism. 2005;54(2):271-4.

33. Barle H, Hammarqvist F, Westman B, Klaude M, Rooyackers O, Garlick PJ, et al. Synthesis rates of total liver protein and albumin are both increased in patients with an acute inflammatory response. Clin Sci (Lond). 2006;110(1):93-9.

34. Erdoes G, Dietrich W, Stucki MP, Merz TM, Angelillo-Scherrer A, Nagler M, et al. Short-term recovery pattern of plasma fibrinogen after cardiac surgery: A prospective observational study. PLoS One. 2018;13(8):e0201647.

35. Fenger-Eriksen C, Jensen TM, Kristensen BS, Jensen KM, Tonnesen E, Ingerslev J, et al. Fibrinogen substitution improves whole blood clot firmness after dilution with hydroxyethyl starch in bleeding patients undergoing radical cystectomy: a randomized, placebo-controlled clinical trial. J Thromb Haemost. 2009;7(5):795-802.

36. Solomon C, Hagl C, Rahe-Meyer N. Time course of haemostatic effects of fibrinogen concentrate administration in aortic surgery. $\mathrm{Br} \mathrm{J}$ Anaesth. 2013;110(6):947-56. 
37. Michalopoulos GK. Principles of liver regeneration and growth homeostasis. Compr Physiol. 2013;3(1):485-513.

38. Starlinger P, Luyendyk JP, Groeneveld DJ. Hemostasis and Liver Regeneration. Semin Thromb Hemost. 2020;46(6):735-42.

\section{Figures}

A

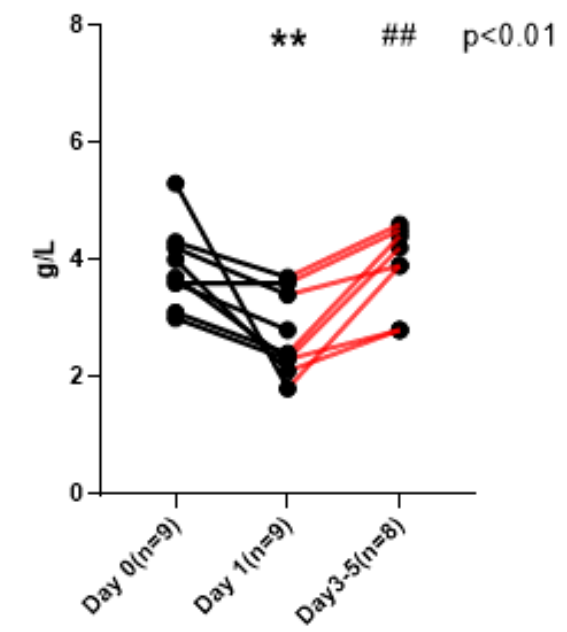

Fibrinogen (pancreas surgery)

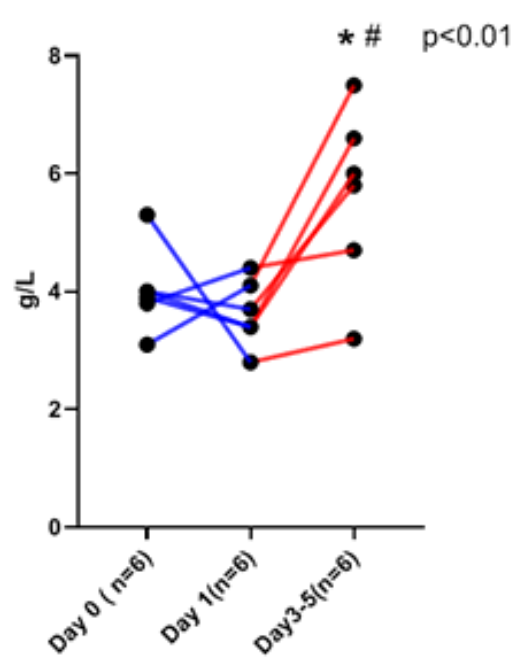

B

Fibrinogen (liver surgery)

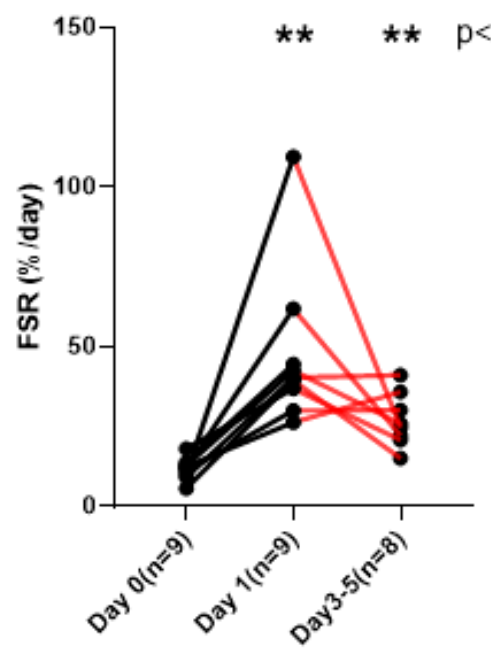

Fibrinogen (pancreas surgery)

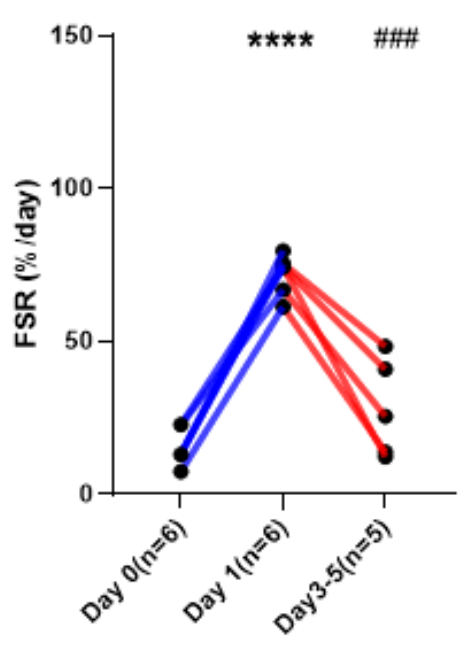

Fibrinogen (liver surgery)

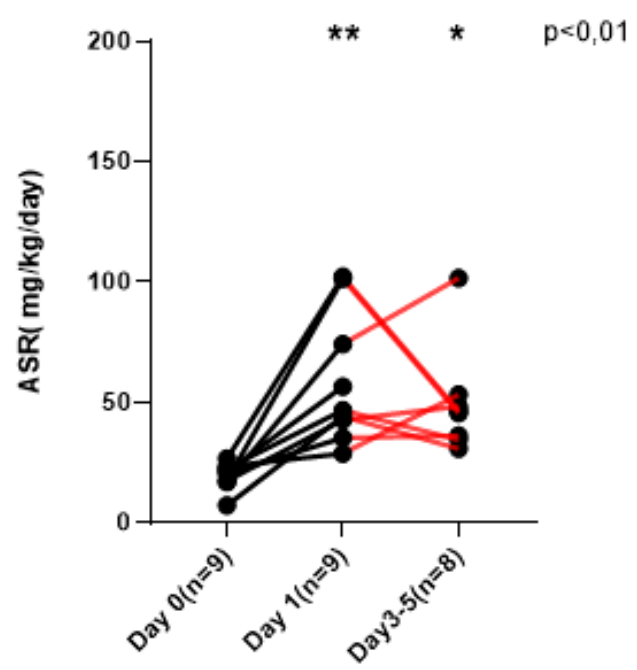

Fibrinogen (pancreas surgery)

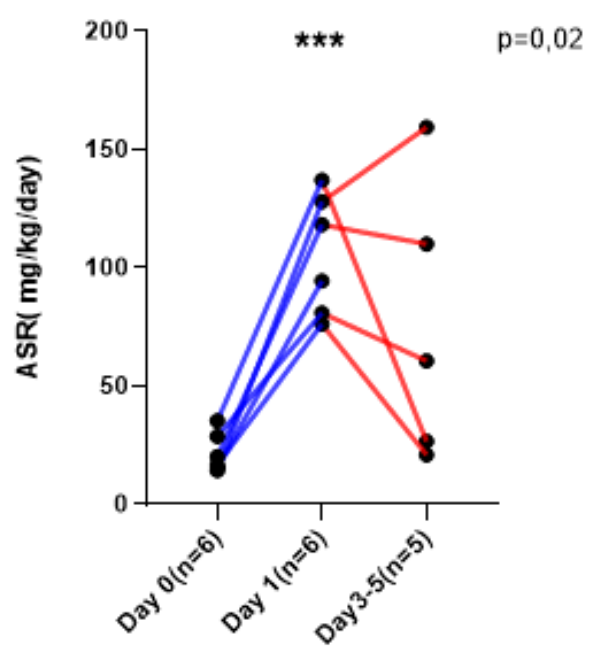

\section{Figure 1}

The fibrinogen plasma concentrations (panel A) and synthesis rates (panel B) in all patients undergoing liver surgery $(n=9)$ and pancreas surgery $(n=6)$. The individual values are depicted as black bold points. Levels of statistical significance for the ANOVA (or mixed-effects model analysis within groups) are given

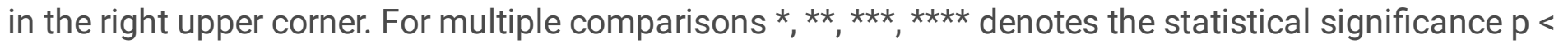


$0.05, p<0.01, p<0.001$ and $<0.0001$ respectively of the difference from preoperative values, while \# have the same significance from postoperative day 1.

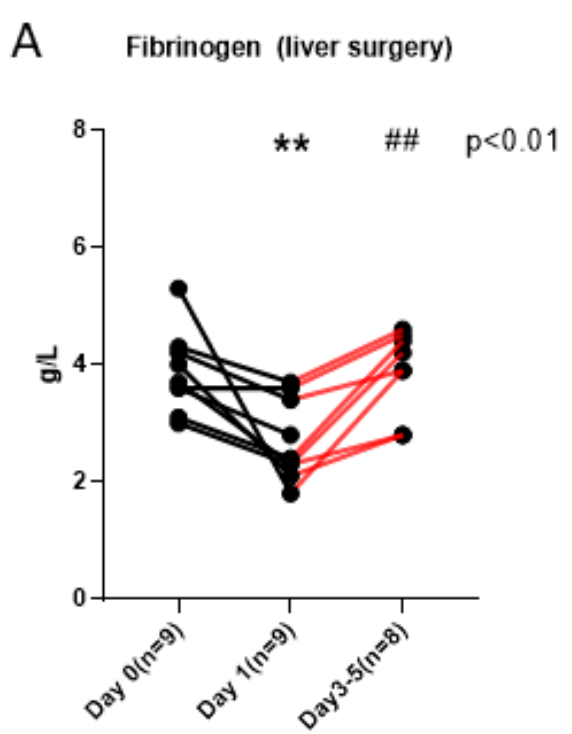

Fibrinogen (pancreas surgery)

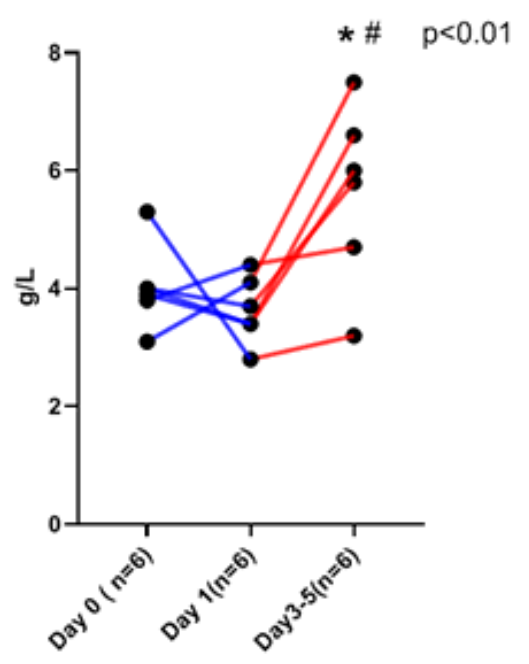

B

Fibrinogen (liver surgery)

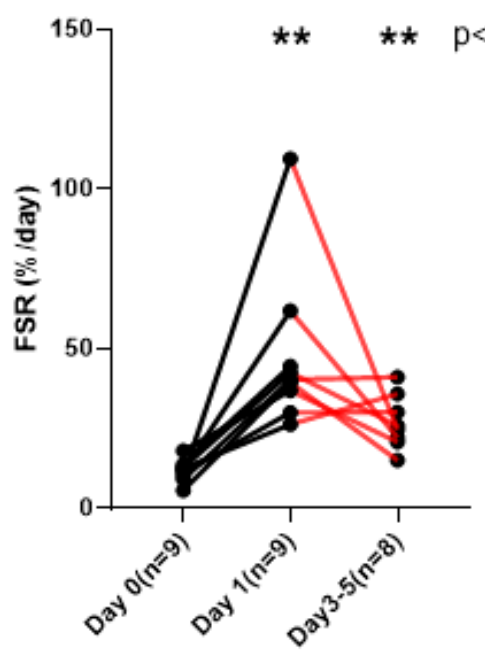

Fibrinogen (pancreas surgery)

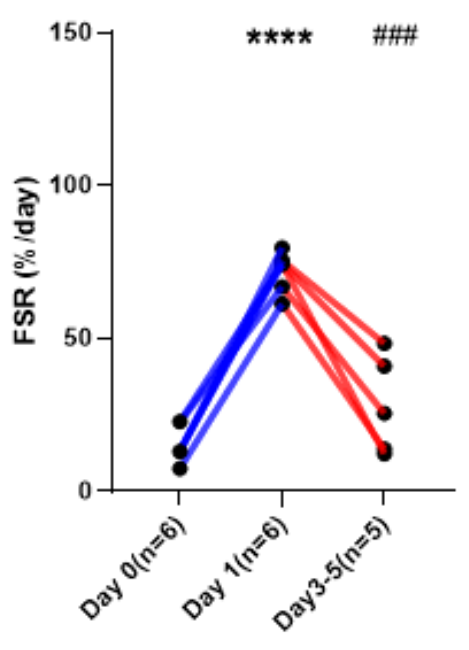

Fibrinogen (liver surgery)

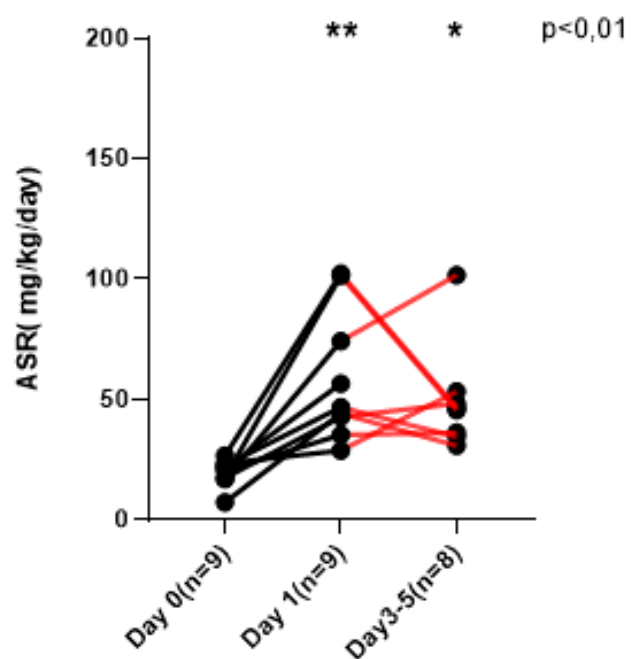

Fibrinogen (pancreas surgery)

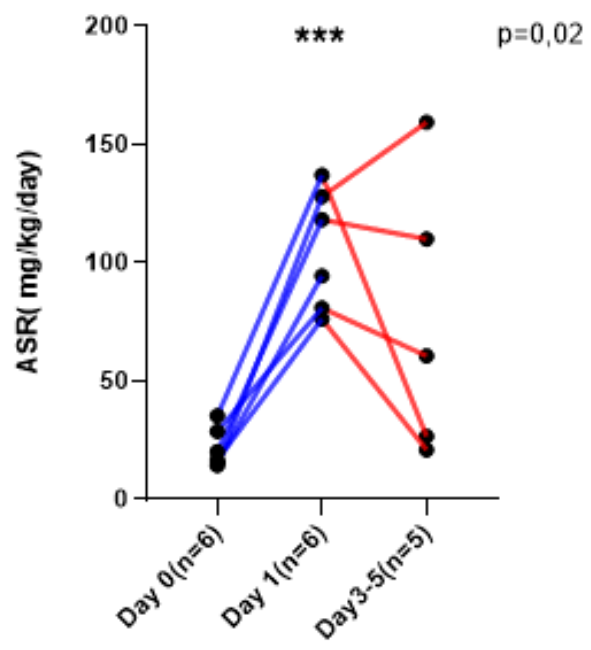

\section{Figure 1}

The fibrinogen plasma concentrations (panel A) and synthesis rates (panel B) in all patients undergoing liver surgery $(n=9)$ and pancreas surgery $(n=6)$. The individual values are depicted as black bold points. Levels of statistical significance for the ANOVA (or mixed-effects model analysis within groups) are given in the right upper corner. For multiple comparisons $*, \star \star, * \star \star, * \star \star \star$ denotes the statistical significance $p<$ $0.05, p<0.01, p<0.001$ and $<0.0001$ respectively of the difference from preoperative values, while \# have the same significance from postoperative day 1. 
A

Fibrinogen (liver surgery)

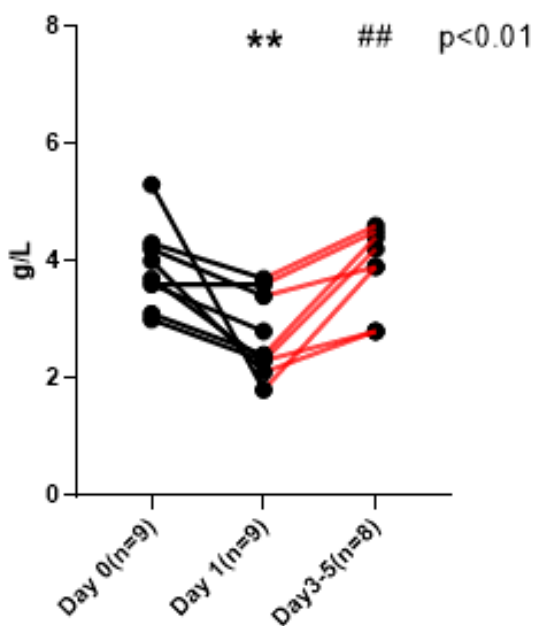

Fibrinogen (pancreas surgery)

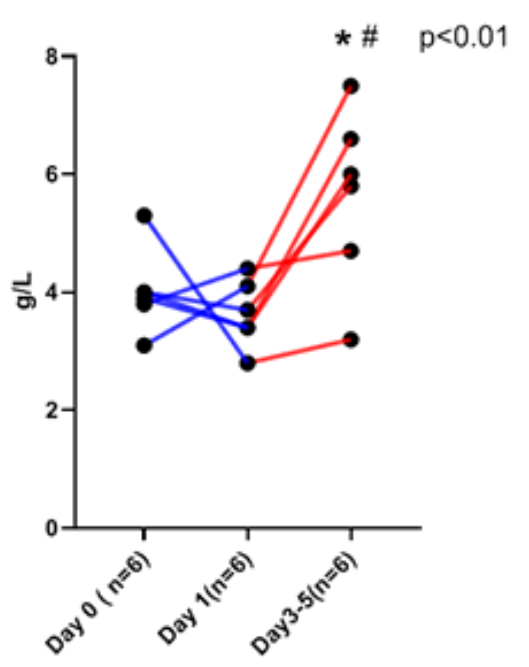

B

Fibrinogen (liver surgery)

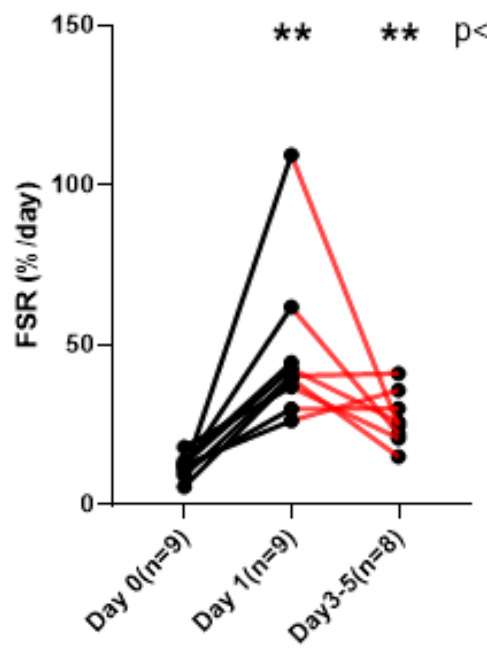

Fibrinogen (pancreas surgery)

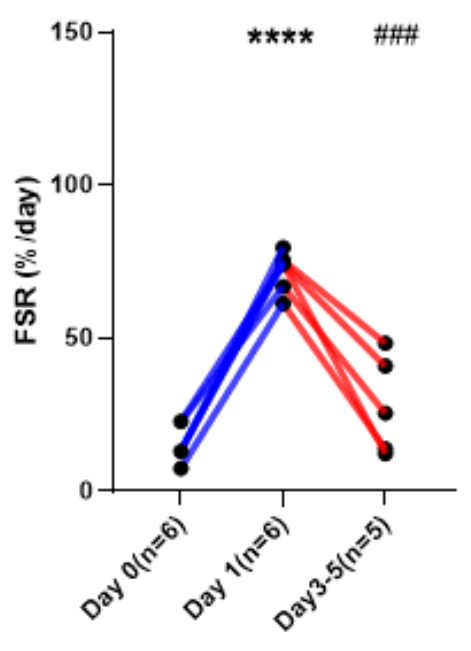

Fibrinogen (liver surgery)

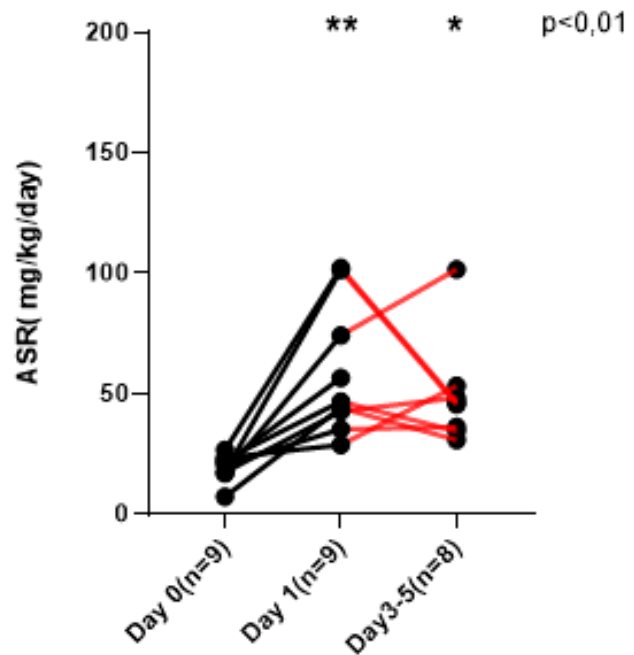

Fibrinogen (pancreas surgery)

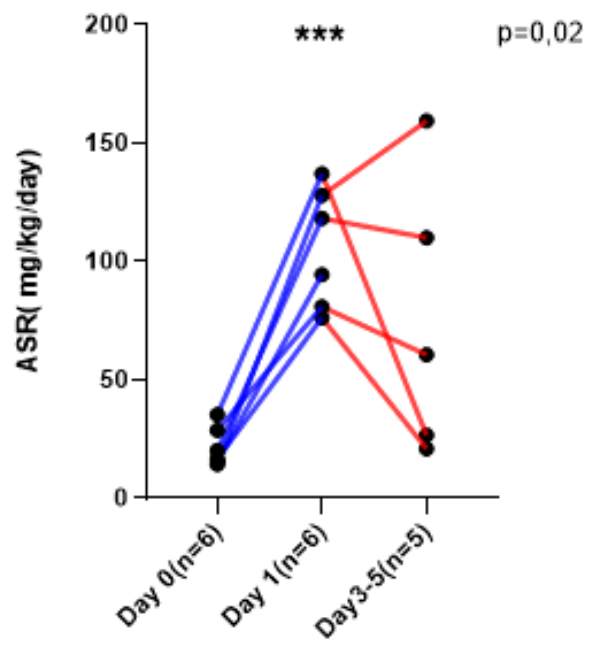

\section{Figure 1}

The fibrinogen plasma concentrations (panel $A$ ) and synthesis rates (panel $B$ ) in all patients undergoing liver surgery $(n=9)$ and pancreas surgery $(n=6)$. The individual values are depicted as black bold points. Levels of statistical significance for the ANOVA (or mixed-effects model analysis within groups) are given

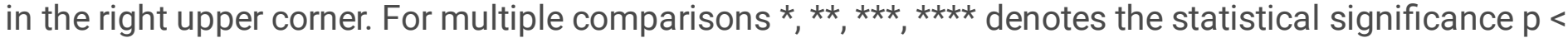
$0.05, p<0.01, p<0.001$ and $<0.0001$ respectively of the difference from preoperative values, while \# have the same significance from postoperative day 1 . 
A

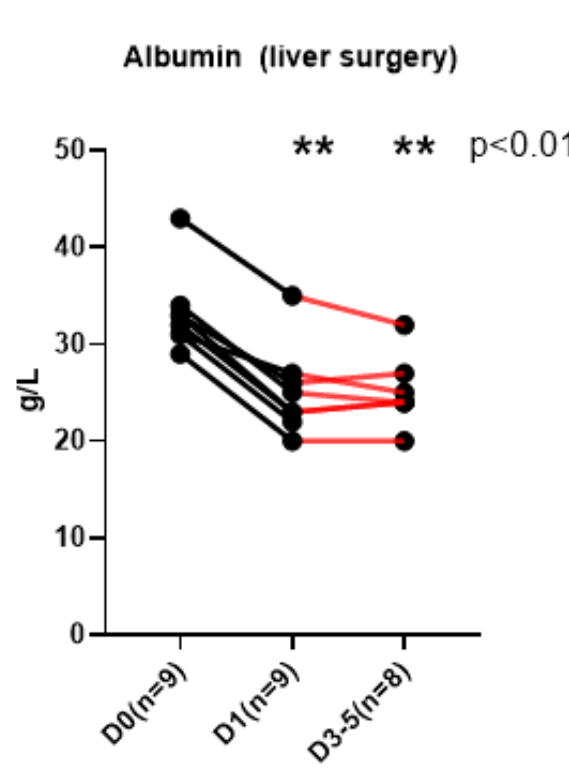

Albumin (pancreas surgery)

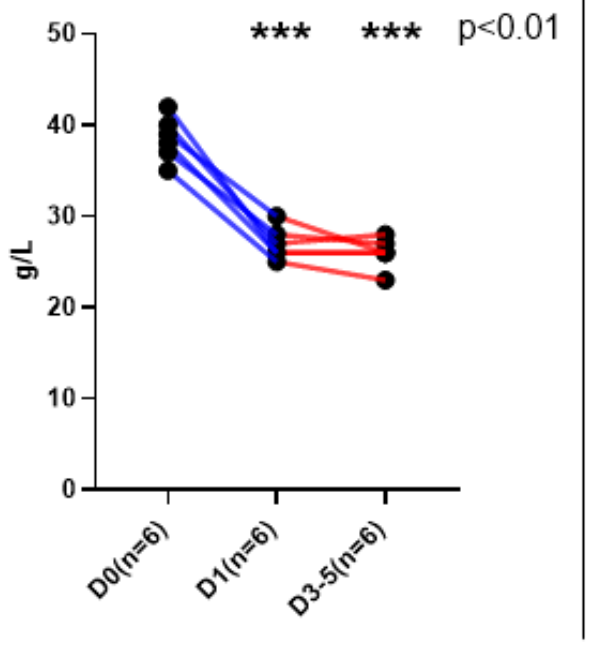

B

Albumin (liver surgery)

Albumin (liver surgery)

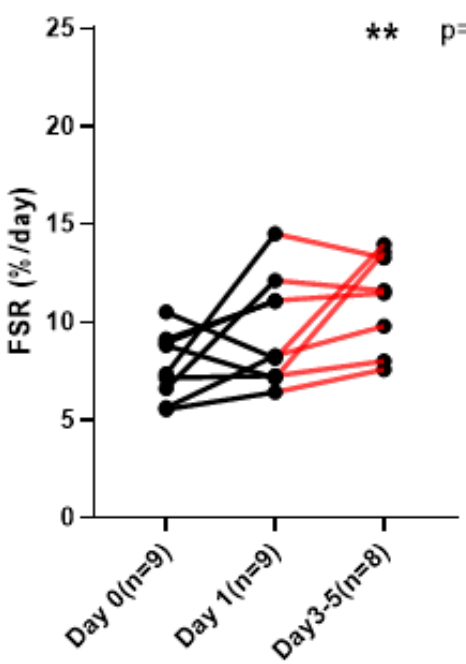

Albumin (pancreas surgery)

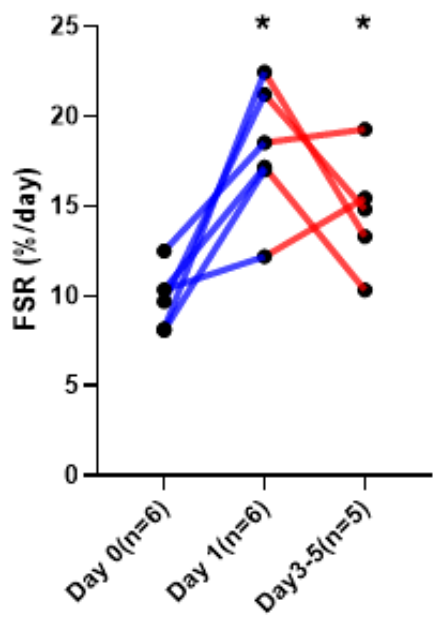

$\mathrm{p}=0,26$

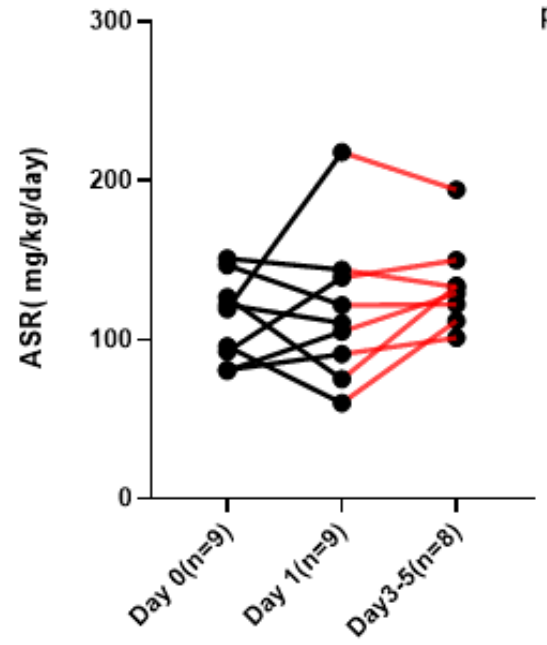

Albumin (pancreas surgery)

$\mathrm{p}<0,01$

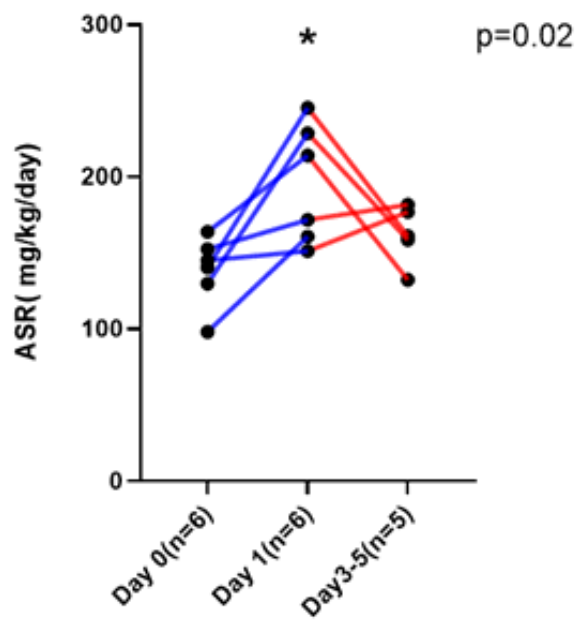

Figure 2

The albumin plasma concentrations (panel A) and synthesis rates (panel B) in all patients undergoing liver surgery $(n=9)$ and pancreas surgery $(n=6)$. The individual values are depicted as black bold points. Levels of statistical significance for the ANOVA (or mixed-effects model analysis within groups) are given in the right upper corner. For multiple comparisons $*, \star \star, \star \star \star, \star \star \star \star$ denotes the statistical significance $p<$ $0.05, p<0.01, p<0.001$ and $<0.0001$ respectively of the difference from preoperative values, while \# have the same significance from postoperative day 1 . 
A

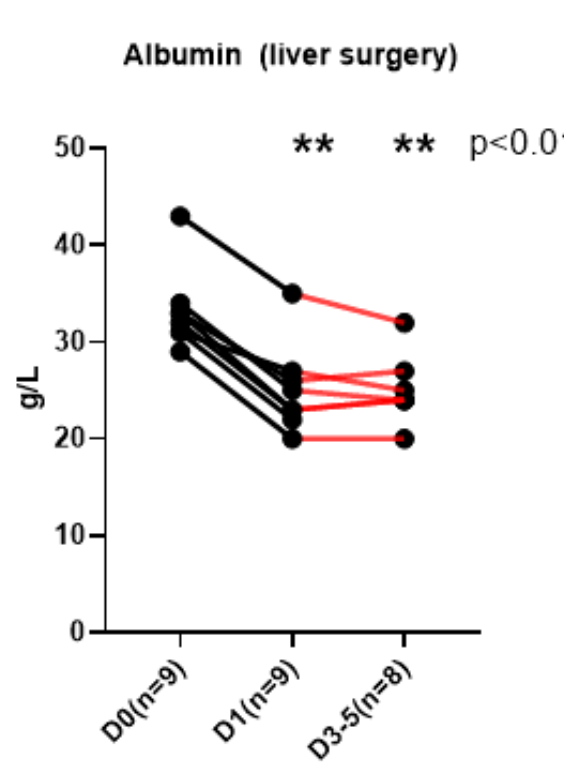

Albumin (pancreas surgery)

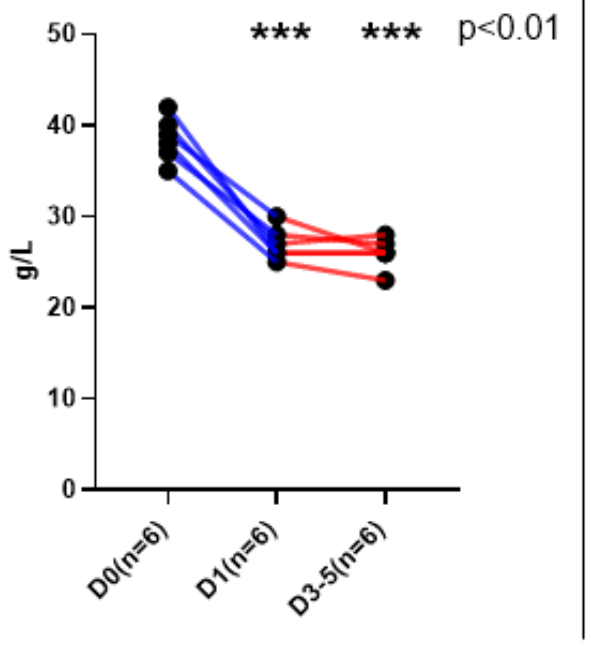

B

Albumin (liver surgery)

Albumin (liver surgery)

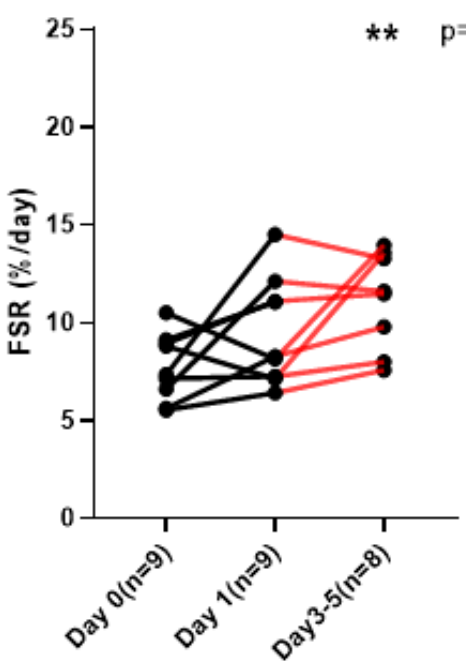

Albumin (pancreas surgery)

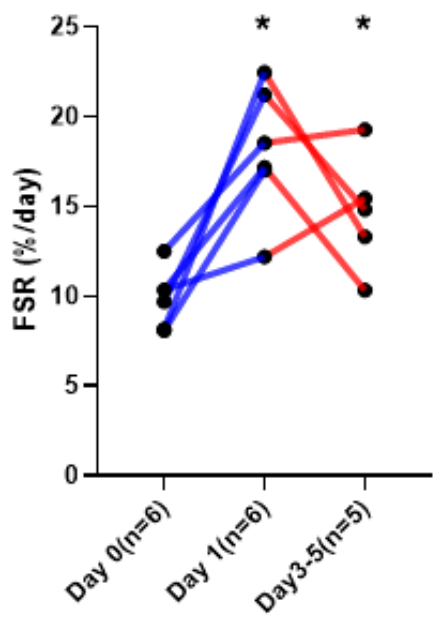

$\mathrm{p}=0,26$

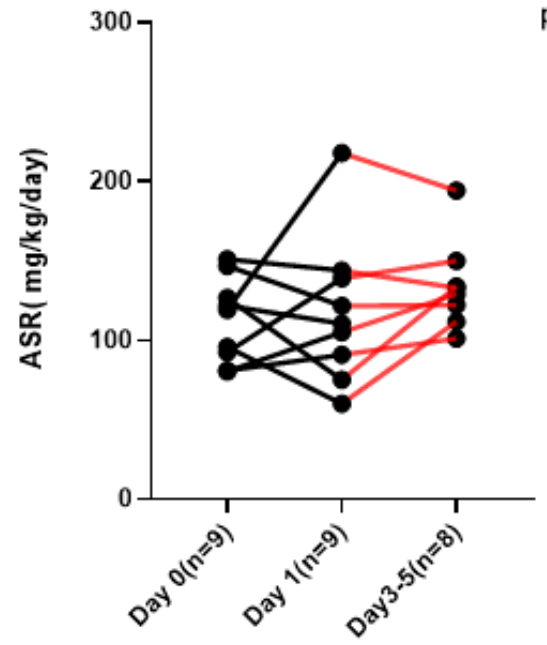

Albumin (pancreas surgery)
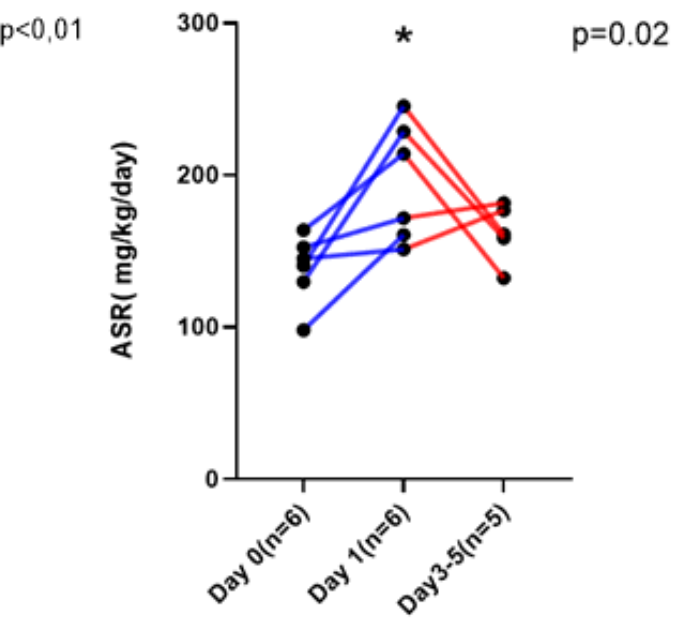

Figure 2

The albumin plasma concentrations (panel A) and synthesis rates (panel B) in all patients undergoing liver surgery $(n=9)$ and pancreas surgery $(n=6)$. The individual values are depicted as black bold points. Levels of statistical significance for the ANOVA (or mixed-effects model analysis within groups) are given in the right upper corner. For multiple comparisons $*, \star \star, \star \star \star, \star * \star \star$ denotes the statistical significance $p<$ $0.05, p<0.01, p<0.001$ and $<0.0001$ respectively of the difference from preoperative values, while \# have the same significance from postoperative day 1. 
A

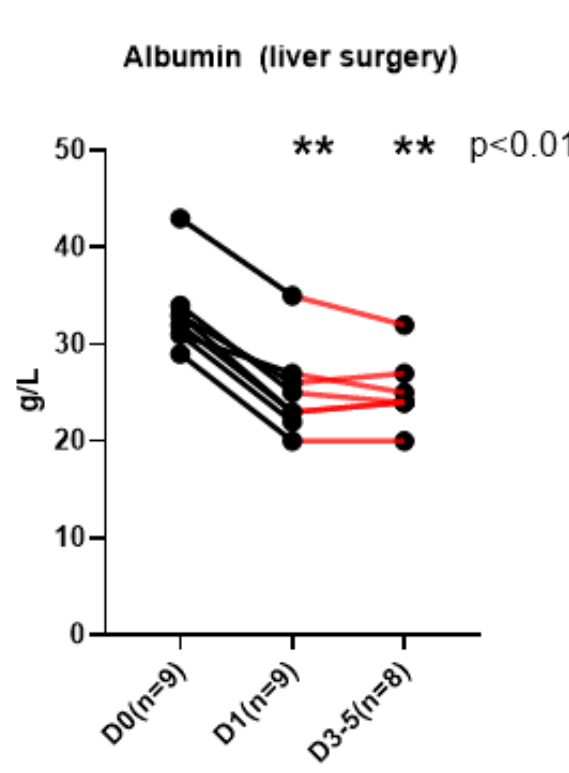

Albumin (pancreas surgery)

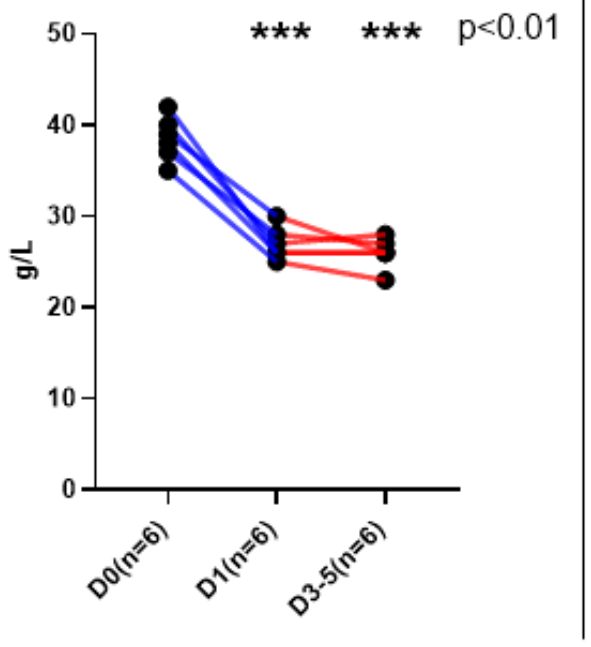

B

Albumin (liver surgery)

Albumin (liver surgery)

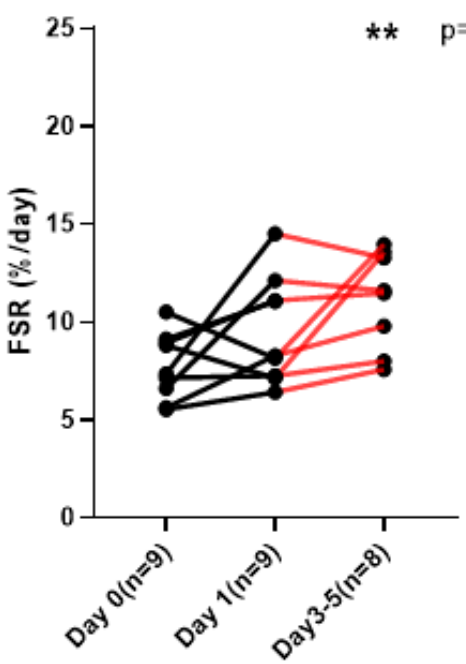

Albumin (pancreas surgery)

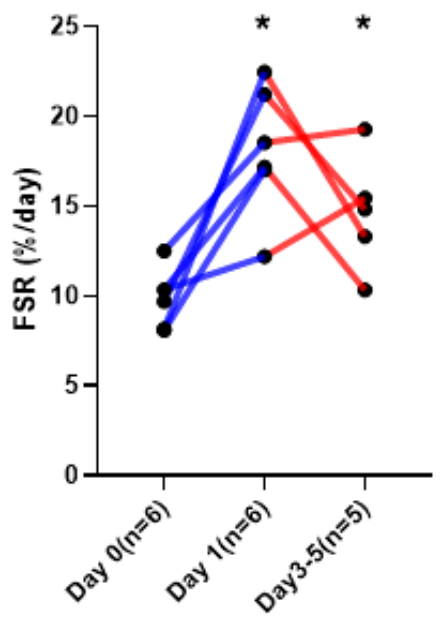

$\mathrm{p}=0,26$

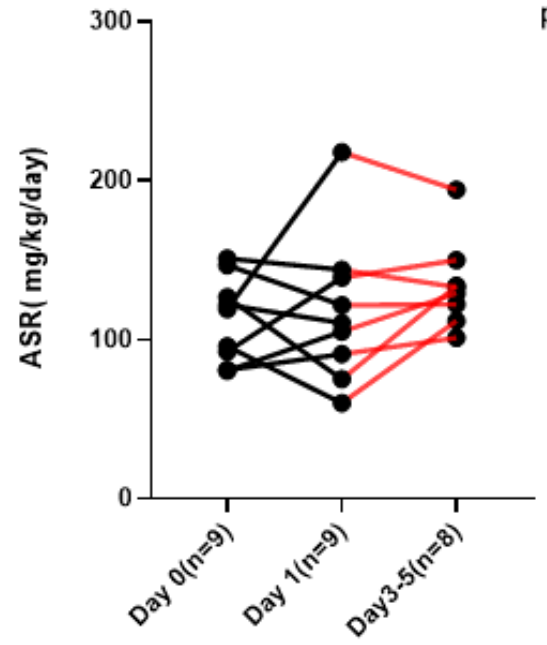

Albumin (pancreas surgery)

$\mathrm{p}<0,01$

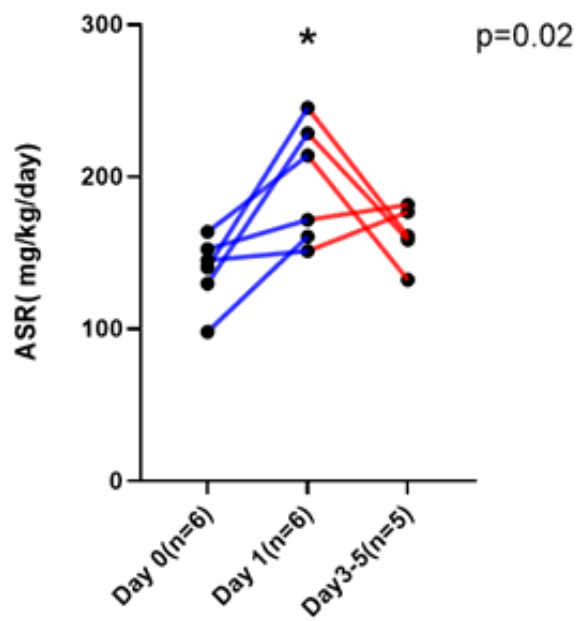

Figure 2

The albumin plasma concentrations (panel A) and synthesis rates (panel B) in all patients undergoing liver surgery $(n=9)$ and pancreas surgery $(n=6)$. The individual values are depicted as black bold points. Levels of statistical significance for the ANOVA (or mixed-effects model analysis within groups) are given in the right upper corner. For multiple comparisons $*, \star \star, \star \star \star, \star \star \star \star$ denotes the statistical significance $p<$ $0.05, p<0.01, p<0.001$ and $<0.0001$ respectively of the difference from preoperative values, while \# have the same significance from postoperative day 1 . 
A
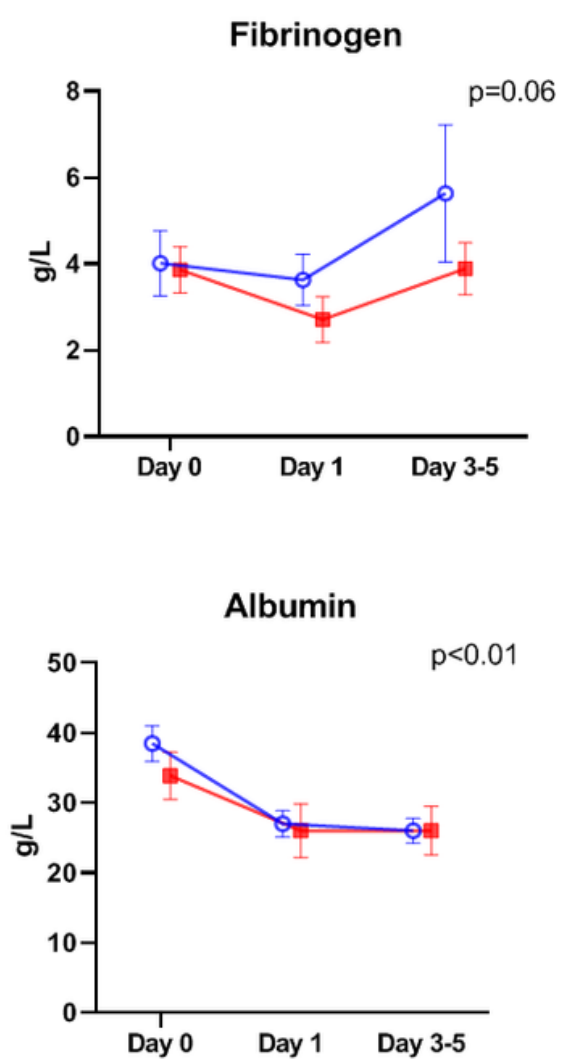

B
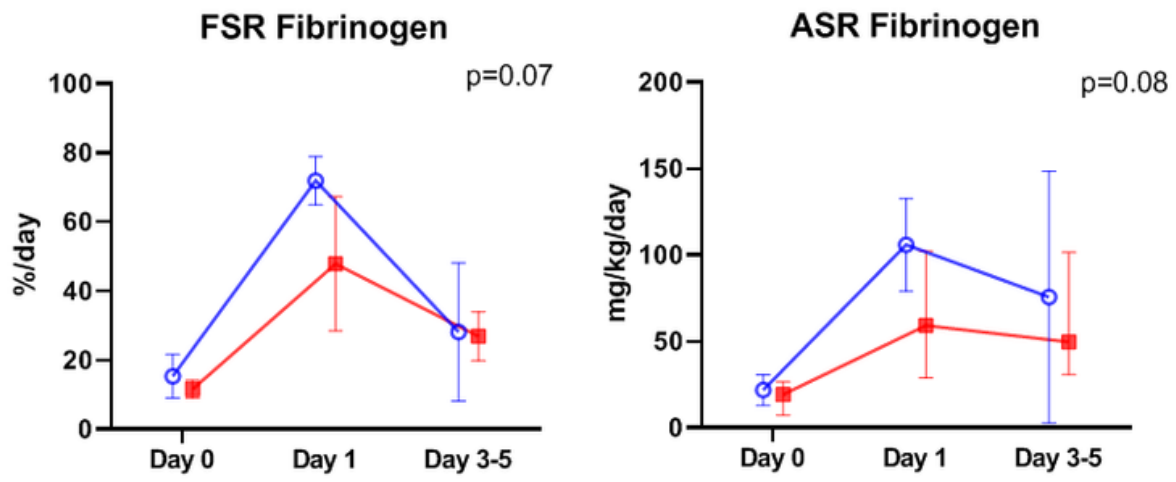

FSR Albumin

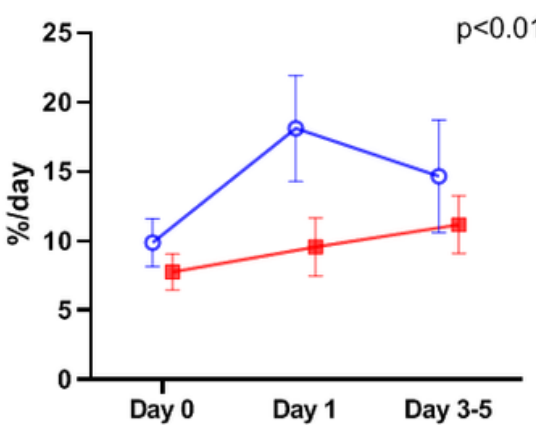

ASR Albumin

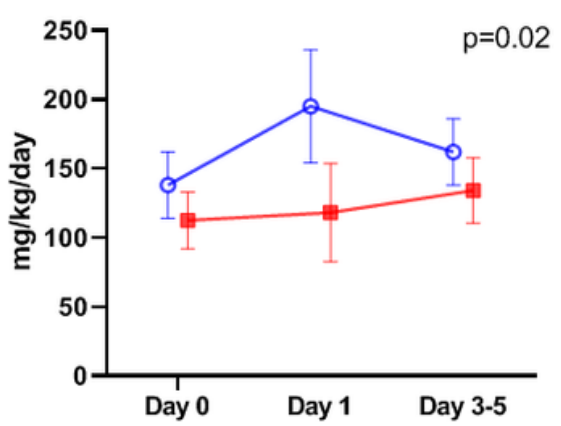

- Liver surgery

$\odot$ Pancreas surgery

\section{Figure 3}

The temporal pattern of fibrinogen and albumin plasma concentrations (panel A) and synthesis rates (panel B) in patients undergoing major liver surgery $(n=9)$ (depicted in red) and pancreas resection $(n=6)$ (depicted in blue). Values are provided as the mean +0.95 confidence intervals and the level of statistical significance for mixed-effects model analysis between groups are given in the upper right corner. 
A
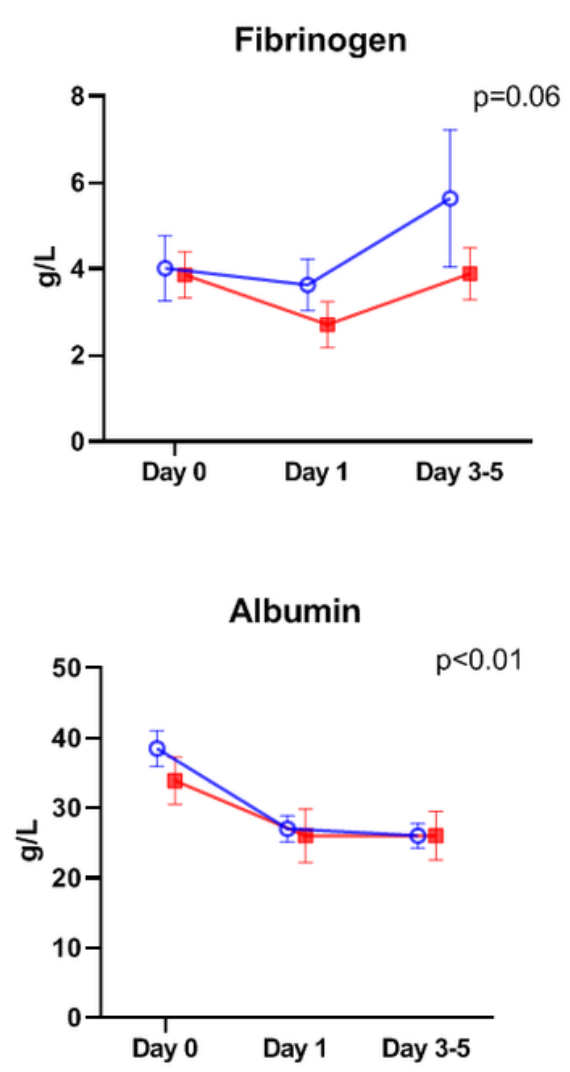

B
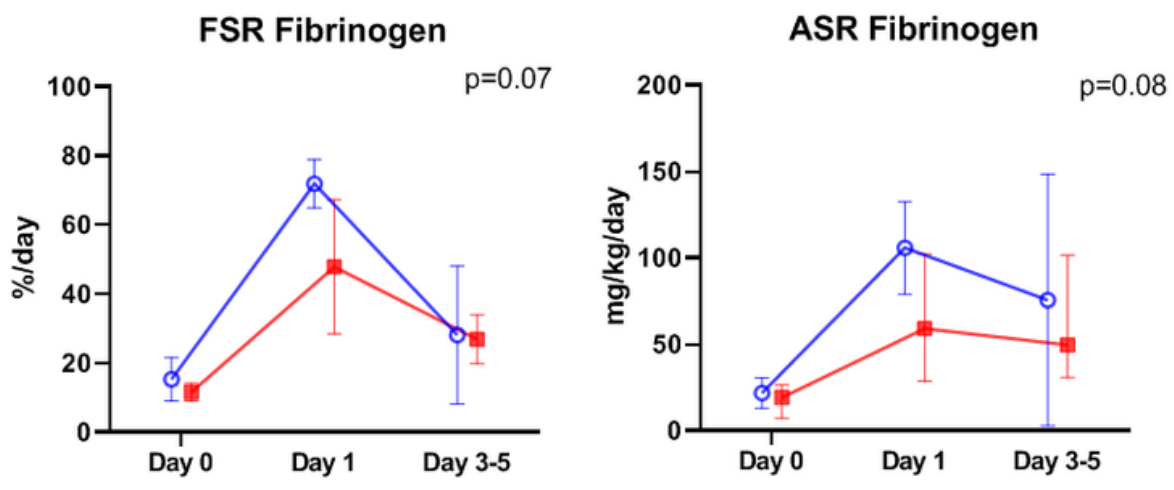

FSR Albumin

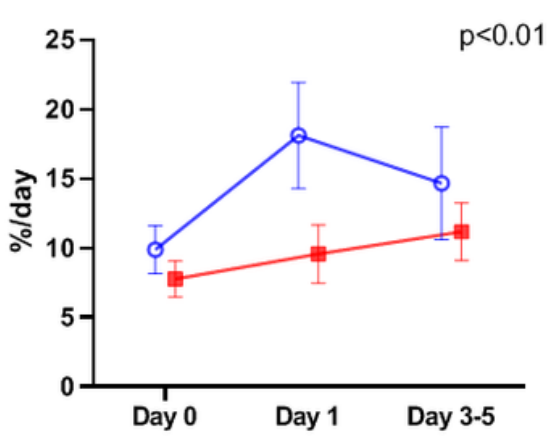

ASR Albumin

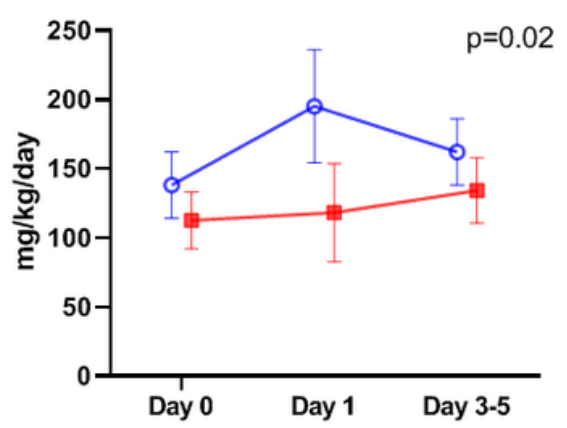

- Liver surgery

๑- Pancreas surgery

\section{Figure 3}

The temporal pattern of fibrinogen and albumin plasma concentrations (panel A) and synthesis rates (panel B) in patients undergoing major liver surgery $(n=9)$ (depicted in red) and pancreas resection $(n=6)$ (depicted in blue). Values are provided as the mean +0.95 confidence intervals and the level of statistical significance for mixed-effects model analysis between groups are given in the upper right corner. 
A
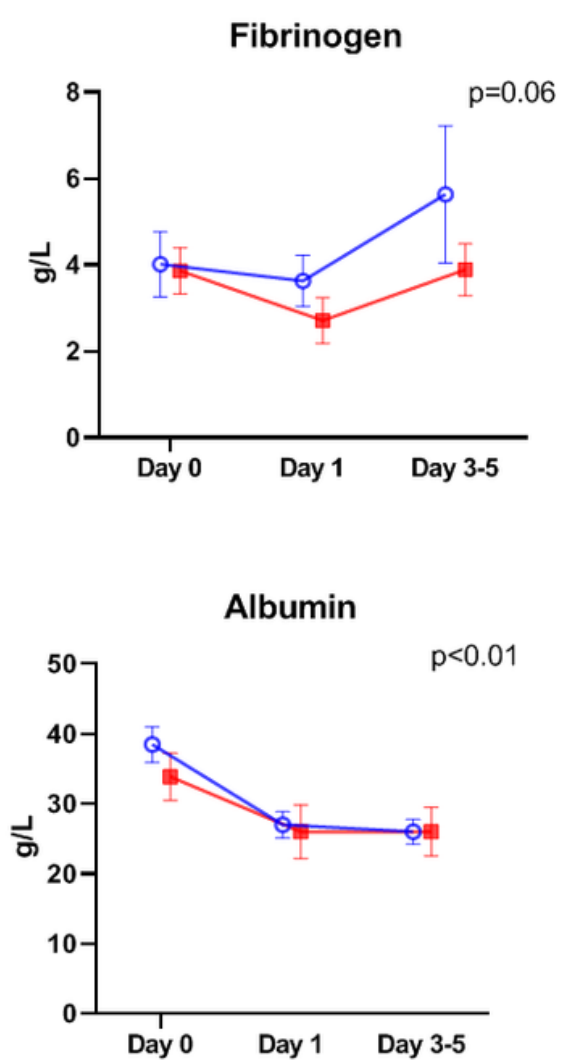

B
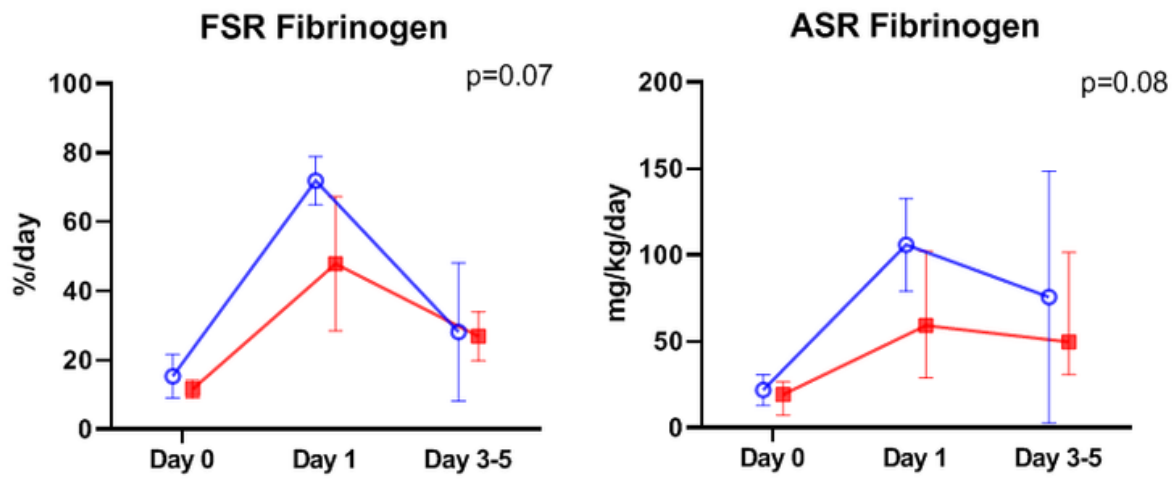

FSR Albumin

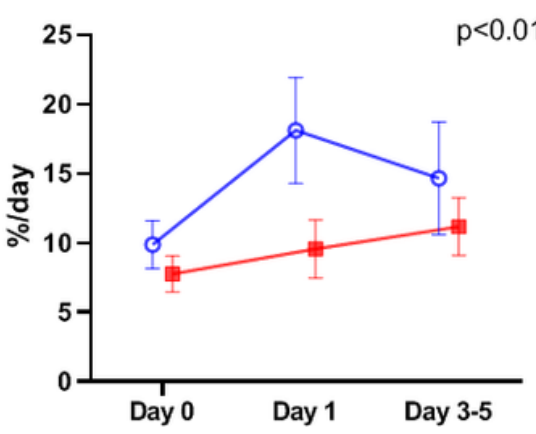

ASR Albumin

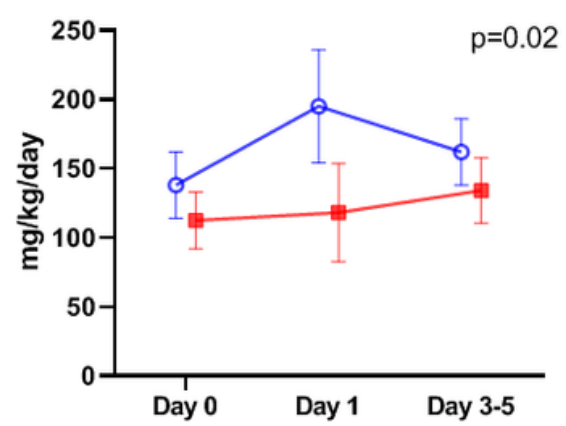

- Liver surgery

$\curvearrowleft$ Pancreas surgery

\section{Figure 3}

The temporal pattern of fibrinogen and albumin plasma concentrations (panel A) and synthesis rates (panel $B)$ in patients undergoing major liver surgery $(n=9)$ (depicted in red) and pancreas resection $(n=6)$ (depicted in blue). Values are provided as the mean +0.95 confidence intervals and the level of statistical significance for mixed-effects model analysis between groups are given in the upper right corner.

\section{Supplementary Files}

This is a list of supplementary files associated with this preprint. Click to download.

- Additionalfile1.pdf

- Additionalfile1.pdf

- Additionalfile1.pdf

- Additionalfile2.pdf

- Additionalfile2.pdf 
- Additionalfile2.pdf

- graphycalabstract.tif

- graphycalabstract.tif

- graphycalabstract.tif 